\title{
From financial instability to green finance: the role of banking and credit market regulation in the Eurace model
}

\author{
Marco Raberto ${ }^{a, *}$. Bulent Ozel ${ }^{b} \cdot$ Linda \\ Ponta $^{a} \cdot$ Andrea Teglio $^{b, c}$. Silvano \\ Cincotti $^{a}$
}

Received: date / Accepted: date

\begin{abstract}
We investigate appropriate banking and regulatory policies aimed at pushing the banking sector to shift from speculative lending, cause of asset bubbles and economic crises, to green investments lending, so to foster the transition to a more energy efficient production technology. For this purpose, we consider an enriched version of the Eurace model, which includes heterogenous capital goods, allowing for different degrees of energy efficiency in the production technology. Credit money in Eurace is endogenous and limited by Basel capital adequacy regulation on the supply side, while on the demand side it is determined by firms' investments and households' house purchasing. We introduce a differentiation of capital requirements according to the destination of lending, demanding higher banks' capital in the case of speculative lending, thus encouraging banks to finance firms investments. As up-to-date capital goods have better energy efficiency in the model design, a higher pace of investments implies also a positive environmental effect. Results suggest that the proposed regulation is able to foster investments and capital accumulation in the short term, improving the energy efficiency of firms. However, reducing mortgages with a restrictive regulation has a negative impact on total private credit, and thus on endogenous money supply, weakening consumption and aggregate demand. In the long term, the contraction of total credit becomes stronger, and the negative outcomes on aggregate demand also affect investments. Therefore, in the long run, the positive effects on capital and energy efficiency become negligible, while the main economic indicators deteriorate. JEL codes: E51, Q58, C63
\end{abstract}

Keywords Green finance · Capital requirements · Energy efficiency · Agent-based modelling

\footnotetext{
(a) DIME, University of Genoa, via Opera Pia 15, Genoa, Italy

(b) Department of Economics, University Jaume I, Castellon, Spain

(c) Department of Economics, Ca' Foscari University of Venice, Italy

(*) Corresponding author: marco.raberto@unige.it
} 


\section{Introduction}

Achieving the goal to limit global temperature increases below 2 deg $\mathrm{C}$ with respect to preindustrial levels, as agreed by 195 countries at the United Nations climate change conference, known as COP21, held in Paris in December 2015, will require enormous investments in the green sectors of the economy. Strongest efforts shall be devoted in particular to fostering the transition of energy production from fossil fuels to renewable sources and to the improvement of energy efficiency in buildings, industries and in the transportation sector.

Year 2015 hits a new record high for global investments in renewable energy projects that, excluding large hydro-electric projects, amounted to $\$ 285.9$ billions, whose more than half have been made in the developing world including China, India and Brazil, see UNEP (2016). However, different studies have pointed out that the size of investment required each year in low carbon sectors to limit the temperature increase to the target should be much higher, i.e. in a range from $\$ 650$ billions to $\$ 1$ trillion, see e.g. IEA (2012); WEF (2013). Therefore, there is a relevant so-called green investment gap that needs to be covered. This however looks a particular challenging task in the present economic environment characterized by low growth in advanced economies and increasing risks in developing ones. Furthermore, green investments are usually characterized by high political uncertainty regarding the real long-term commitment of public policies of support, by long-term time horizon and very high initial capital costs (Nelson and Shrimali (2014)). These features make low-carbon investments unattractive to private investors in absence of a strong and sizeable long-term commitment by the government to some form of public support.

The most well-known and discussed solution to the low-carbon investment challenge has been the introduction of a price on carbon (Nordhaus (2013); WB (2015)), either through a carbon tax, i.e. a tax on the carbon content of goods and services, or through a cap-and-trade system of emissions allowances, with the aim to address the market failure related to the exclusion of environmental costs from the market pricing system. The rationale is that a carbon price would push private agents to correctly internalize environmental costs and therefore to perform the appropriate green investments aimed to reduce them. However, carbon price mechanisms still have strong political opposition $^{1}$ on the grounds that they are harmful for business and can damp economic growth.

Beside carbon pricing, a new idea that is gaining attention concerns the design of appropriate banking regulation policies aimed to push banks to lend to lowcarbon activities so to easy the green investment gap, see e.g. Rozenberg et al. (2013); Ferron and Morel (2014); Aglietta et al. (2015); Campiglio (2016). A banking regulatory framework, where banks that lend to firms undertaking

\footnotetext{
1 See e.g. the repeal of the carbon tax by the new Australian government in 2014 or the debate in the US 2016 presidential race
} 
green investments are required to respect looser requirements, could indeed manage to direct credit towards the green sector and therefore reduce the green investment gap. In particular, according to Campiglio (2016), differentiating reserve requirements on the base of the green orientation of the financed investment is the policy most seriously considered. However, the author is also skeptical about the validity of this policy proposal; in particular in advanced economies, where reserves are not actually binding, because central banks usually control the price of reserves (the interest rate) and not the quantity of reserves, and private banks are never rationed in their reserve demand. This is the reason why the author lays down a new proposal about differentiating capital requirements and not reserve requirements, as according to the Basel regulatory framework. The advantage is that capital ratios are actually binding in advanced economies. In particular, Campiglio (2016) states: "An analogous proposal involves setting differentiated capital requirements; that is, imposing different capital adequacy ratios according to the characteristics of the banking institute and the type of lending they provide. Capital requirements are likely to be more effective than liquidity ones in constraining bank lending, as even creating new central bank reserves would not change the capital ratio, or at least not in the way banks desire. Therefore, implementing a regulatory framework where banks that lend to low-carbon (or other socially useful) sectors are required to respect looser requirements could fruitfully manage to direct larger flows of new credit creation towards them. A similar proposal involves calibrating the computation of Basel III risk-weighted capital ratios in a way that low-carbon activities would exert a lower pressure than alternative investments."

To this purpose, the most important contribution of the paper consists in testing this innovative green macro-prudential policy proposal in a computational environment.

In this paper, we investigate the banking regulatory provision that differentiates the capital adequacy ratio according to the type of lending. In particular, we employ an agent-based macro-economic model and simulator to study the effectiveness and the long-run impact on the economy of this type of regulatory provision. A number of agent-based macro models ${ }^{2}$ have been proposed in recent years to address the known limitations of the traditional DSGE modelling approach in macroeconomics, see Fagiolo and Roventini (2016) for a comprehensive review and comparison of the two approaches. Furthermore, agent-based macro-models are going to be applied also to study climate change economics and investigate related policies, see e.g. Balint et al. (2017) for a compressive review and Farmer et al. (2015) for a general discussion about the potential advantages of agent-based models with respect to integrated assessment models, which are the usual workhorse in the field. In particular, Gerst

2 A non-exhaustive list could include the K+S model, see Dosi et al. (2010, 2013, 2015), the set of models developed by the Ancona research group (Caiani et al. (2015); Riccetti et al. (2015); Russo et al. (2016)), the CC-MABM (Assenza et al. (2015)), the Mark I CRISIS model (Klimek et al. (2015); Gualdi et al. (2015)), Iceace (Erlingsson et al. (2014)), Eurace (Cincotti et al. (2012a)) and Eurace@UNIBI (Dawid et al. (2016)) 
et al. (2013) and Tonelli et al. (2016) are among the first attempts to address sustainability issues by means of the agent-based approach. The flow-of-fund dynamic Eirin model (Monasterolo and Raberto (2018)), where agents are identified with the different sectors of the economy, can be considered among the first pioneering attempts in the same direction.

In this respect, we claim that the agent-based modelling approach is particularly suited to encompass the relevant features needed to address our research question, such as the endogenous nature of money created by the banking system in modern economies, see e.g. McLeay et al. (2014); Werner (2014), and the non-equilibrium evolutionary dynamics of the economy (Kaldor (1972); Arthur (2006)).

For the purposes of our study, we employ the agent-based macroeconomic model and simulator Eurace, in particular the most recent version including housing assets, a related market and mortgage lending, see Ozel et al. (2016), that we further enrich with two relevant new features to address the research question of the paper.

The first feature regards a new design of banking regulation that follows a proposal by Campiglio (2016), which suggests the adoption of different capital adequacy ratios according to the type of lending that banking institutions provide. Accordingly, we have designed a set of computational experiments characterized by capital requirements for mortgages that can be higher or lower than a reference value, i.e. $10 \%$, which is the basic capital requirement value adopted for firms' loans. The rationale behind this choice is the assumption that loosening credit access for house purchases may produce asset bubbles with destabilizing effects for the real economy, while loans to business firms are aimed to increase and renew their capital endowment with positive effects for the productive capacity of the economy and for environmental sustainability.

It is worth noting that our working hypothesis is not strictly a behavioural assumption about the attitude of the different types of borrowers (households or firms) on the use of the borrowed funds for speculation (households) or for productive investments (firms). Indeed, house purchase decision making by households is not driven by any speculative purpose but it is mostly random (Ozel et al., 2016). Actually, we are not interested here in households' behavior, but we are more interested in the macroeconomic and credit aspects of the housing market, and in particular in the impact of mortgage loans on the economy as a whole. We do not intend to mimic households' behavior in the housing market but we want to include this market as an important destination of credit in the economy. Therefore, our main research questions is about the effects of loose credit conditions, depending on the destination of the borrowed funds. In this respect, we should consider that over-lending to the business sector has downside risks due to increasing insolvency rates for firms but also positive effects on productive capacity and energy efficiency (in our model) of the economy. On the contrary, easy mortgage lending gives rise to price bubbles and incentivizes speculative house purchase.

Both theoretical and empirical studies support our assumption. The relevance 
of credit dynamics for business cycles is central in the Minskys financial instability hypothesis (Minsky, 1986) and has been also pointed out by theoretical models within the neoclassical school, see e.g. Bernanke and Gertler (1989) and Kiyotaki and Moore (1997). Furthermore, more recently, a large number of explanations proposed about the financial crisis highlight the credit boom occurred in the mid 2000s, in particular in relation to mortgage lending practices and the related housing bubble (see e.g. Keen et al. (2009); Turner (2013); Muellbauer (2015), along with the ensuing subprime crisis that is considered the triggering cause of the 2007/2008 financial crisis (Duca et al., 2010). In this respect, extensive empirical research shows the connection between credit and housing bubbles and bursts, see e.g. Baker (2008) for US, Xiao and Devaney (2016) for UK and Ruiz et al. (2015) for Spain.

Finally, the second relevant feature of our model design regards the heterogeneity of capital goods with respect to energy efficiency ${ }^{3}$ that we assume exogenously increasing over time. This new model provision implies that investments in capital goods provide also an environmental benefit as the new vintages are characterized by higher energy efficiency and then allow the production of consumption goods at a lower energy intensity per unit of consumption good produced. Investment decision making is then also updated accordingly to take into account the intertemporal saving of energy per unit of consumption goods produced due to investment decision.

The paper is structured as follows: Section 2 outlines the agent-based macroeconomic model we have employed and Section 3 presents the computational experiments performed and discusses the relevant results. Concluding remarks are drawn in section 4 .

\section{The enriched Eurace model}

\subsection{Model overview}

Eurace is an agent-based macroeconomic model and simulator that has been developed in the last ten years within two EU-funded projects ${ }^{4}$, see Cincotti et al. (2010, 2012a,b); Raberto et al. (2012); Teglio et al. (2012); Raberto et al. (2014); Teglio et al. (2017); Ponta et al. (2018). The baseline Eurace model includes different types of agents: households (HHs), which act as workers, consumers and financial investors; consumption goods producers (CGPs), henceforth firms, producing a homogenous consumption goods; a capital goods producer (KGP); commercial banks (Bs) and two policy makers agents, namely a government $(\mathrm{G})$ and a central bank $(\mathrm{CB})$, which are in charge of fiscal and monetary policy, respectively.

\footnotetext{
3 It is worth noting the relevance of energy efficiency in the EU environmental policy framework where a $20 \%$ increase in energy efficiency by 2020 with respect to 1990 is among the three well-known 20-20-20 targets set by the European Union in 2009, see: http://eur-lex.europa.eu/legal-content/EN/TXT/?uri=CELEX:32009D0406

4 FP6 European Project EURACE and EU-FP7 project SYMPHONY
} 
Agents' behavior is modelled as myopic and characterized by limited information, scarce computational capabilities and adaptive expectations. The details about agents' decision making in the baseline Eurace model are described in Teglio et al. (2017). Agents interact through different markets where consumption and capital goods, labor and credit are exchanged in a decentralized setting with disperse prices set by suppliers and based on costs. Moreover, households interact in the housing market. The housing market is characterized by households that sell or buy homogeneous houses units subject to budget constraints. If a prospective buyer needs a mortgage, she/he can send a request to a bank, which provides the mortgage only if the expected future income of the potential buyer is deemed sufficient to face scheduled mortgage payments and the bank itself satisfies Basel capital requirements conditions. Households can assume the role of buyer or seller in the housing market with an equal exogenous probability. The reason of this random selection is that we are interested on the macroeconomic and credit implications of the housing market, and in particular on the impact of mortgage loans on the economy as a whole. However, we allow also for a special case, called fire sale case, where households enter the housing market because financially distressed (when mortgages payments have exceeded a given fraction of their income) and are forced to sell their houses at a discounted price in order to reduce mortgage payments and debt burden. Trading in the housing market is decentralized, prices are posted by sellers while prospective buyers are randomly queued to choose the available housing unit at the lowest price.

The full details about the housing market in Eurace as well as the different conditions for mortgages lending and their effects on the housing price and the economy can be found in Ozel et al. (2016). Appendix A1 of this paper reports the most relevant features of the housing market in Eurace.

In order to investigate the appropriate banking and regulatory policies aimed to force the banking sector to move away from speculative lending, cause of asset bubbles and economic crises, to the financing of the green sector, an enriched Eurace model has been designed. The new model includes an energy sector, where electricity production is based on fossil fuels. In particular, electricity is an additional production factor used by consumption goods producers, which use heterogeneous capital goods characterized by endogenous electricity efficiency. Finally, we designed banks' capital requirements which can vary according to the type of lending, i.e. loans to business firms or mortgages to households.

Consumption goods producers (CGPs) need electricity, in addition of labor and capital, as a production input. The electricity efficiency of the production process is not constant but depends on the composition of the capital goods vintages in the capital endowment of every firm (CGP). The lower the average age of capital goods of a firm, the higher the energy efficiency of production, or equivalently, the lower the energy intensity of production, i.e. the amount 
of electricty/energy ${ }^{5}$ required per unit of output.

Banks' capital adequacy ratios have been differentiated with respect to the type of lending, namely loans to business firms or mortgages to households for house purchases.

Figure 1 shows a graphical representation of the model's structure, where the novel features are highlighted with respect to the previous versions. In particular, rectangles represent the different type of agents and the arrows the relations among them in terms of current account monetary flows. The new features are highlighted in bold and yellow and consist in the energy sector schematised by the power producer and the foreign economy.

The following two subsections will provide the modelling details about the use of energy sector and the energy efficiency of the production sector as well as about the differentiation of banks' capital requirements.

\subsection{The energy sector and energy efficiency}

We assume that to produce the amount $q_{C_{f}}$ of consumption goods, firm $f$ needs an appropriate number of employees and an appropriate capital endowment, as fixed by the Cobb-Douglas technology, see (Teglio et al., 2017, Appendix, Eq. 8). In this new setting the firms also needs an amount of energy, say $q_{E}$, determined by the equation:

$$
q_{E}=\epsilon_{f} q_{C_{f}}
$$

where $\epsilon_{f}$ is a firm-specific energy intensity variable that gives the energy amount required per unit of output. We assume no substitutability between energy and the other two inputs, i.e. labor and capital. CGPs are never rationed in their energy demand which is immediately delivered by the power producer agent ${ }^{6}$ on request at a price $p_{E}$ which is determined by a fixed markup $\mu_{E}$ on the price of fossil fuels, $p_{O}$. The price of fossil fuels is exogenously given and assumed to be subject to an exponentially monthly growth rate $\xi_{O}$. Energy costs $p_{E} q_{E}$ are a variable cost that is taken into account by the firm in addition to labor costs, interest rates and capital depreciation in the determination of unit costs of output, see (Teglio et al., 2017, Appendix, Eq. 10). Thus energy costs have also an impact on consumption goods prices.

Energy intensity $\epsilon_{f}$ is determined by the different vintages of capital goods owned by firm $f$. We assume that each unit of capital goods, when employed in the production process by the firm, requires an amount of energy per unit of output, i.e. an energy intensity $\epsilon_{K}$, that depends on the time the capital good

\footnotetext{
5 In the paper, we will use the terms electricity and energy interchangeably, with no distinction.

6 The power producer (PP) agent is a very stylized agent that imports fossil fuels from the foreign sector at price $p_{O}$ and produces electricity on request with no labor force needed. PP profits are given by the aggregate amount of energy consumed by the production sector, multiplied by difference between between $p_{E}$ and $p_{O}$. PP profits are paid out to shareholders (households) in the Eurace economy.
} 
has been manufactured by the capital goods producer (KGP) and delivered to the firm (CGP). In particular, we assume that, due to technological progress ${ }^{7}$, the capital goods producer is able to manufacture capital goods characterized by an energy intensity $\epsilon_{K}$ which decreases exponentially over time at the monthly rate $\xi_{K}$.

The energy intensity of each firm then decreases over time according to the size and timing of its investment decisions. When a firm $f$ makes an investment $\Delta K_{f}$, its energy intensity decreases according to the weighted average:

$$
\epsilon_{f}=\frac{\widehat{\epsilon}_{f} K_{f}+\epsilon_{K} \Delta K_{f}}{K_{f}+\Delta K_{f}},
$$

where $\widehat{\epsilon}_{f}$ was the electricity intensity characterizing the production process of the firm before the investment, while $\epsilon_{K}$ is the electricity intensity of the new vintages of capital goods $\Delta K_{f}$.

As $\epsilon_{K}$ is supposed to decrease exponentially over time due to an exogenously given technological progress, firm specific electricity intensity $\epsilon_{f}$ improves over time due to new investments; therefore, investment decision making, based on net present value calculations, needs to take into account not only the additional positive cash flows from sales due to the higher productive capacity, as stated in (Teglio et al., 2017, Appendix, Eq. 3), but also the negative cash flow related to the energy expenses due to the additional output, as well as the positive cash flows given by the savings of energy expenses per unit of output because of the lower average $\epsilon_{f}$. In particular, firm $f$ chooses the investment $\Delta K_{f}$ that maximizes a net present value NPV given by three terms as follows:

$$
N P V=N P V^{\text {old }}+P V^{(1)}+P V^{(2)},
$$

where $N P V^{\text {old }}$ takes into account the present value of additional future revenues, due to the expanded production capacity, net of the present cost of capital, as showed in (Teglio et al., 2017, Appendix, Eq. 3), whereas $P V^{(1)}$ and $P V^{(2)}$ are given by the following equations:

$$
\begin{aligned}
& P V^{(1)}=-\sum_{m} \frac{p_{E} \epsilon_{f} \Delta_{m} q_{C_{f}}}{\left(1+\frac{r_{K_{f}}}{12}\right)^{m}} \\
& P V^{(2)}=+\sum_{m} \frac{p_{E} \Delta \epsilon_{f} q_{C_{f}}}{\left(1+\frac{r_{K_{f}}}{12}\right)^{m}}
\end{aligned}
$$

where $r_{K_{f}}$ is the yearly weighted average cost of capital for firm $f, \Delta_{m} q_{C_{f}}$ is the additional output ${ }^{8}$ at future month $m$ given by the planned investment,

\footnotetext{
7 This assumption is supported by empirical evidence. In particular, the latest Energy Efficiency Market Report by the International Energy Agency points out that global energy intensity improved by $1.8 \%$ in 2015 and by $1.5 \%$ in 2014, while the average yearly improvement was around $0.6 \%$ in the decade between 2003 and 2013 (IEA (2016)).

8 It is worth noting that the additional output is assumed to be a decreasing function of $m$ to take into account the investments depreciation, see (Teglio et al., 2017, Appendix, Eq. $5)$.
} 
$\Delta \epsilon_{f}$ is the decrease in energy intensity due to investments and $q_{C_{f}}$ is the previous production level. Therefore, equations (3) and (4) assess the present value of additional expected cash flows related to energy expenses, following the investment in new capital goods. In particular, the additional production amount $\Delta_{m} q_{C_{f}}$ at month $m$, due to investment, entails an additional energy cost of amount $p_{E} \epsilon_{f} \Delta_{m} q_{C_{f}}$, where $p_{E}$ is the expected energy price and $\epsilon_{f}$ is the present energy intensity (after investment). Equation (3) computes $P V^{(1)}$, i.e. the present value of negative cash flows following these higher energy expenses due to the output increase. Furthermore, the investment in new capital goods provide an increase in energy efficiency and a consequent energy intensity decrease $\Delta \epsilon_{f}$ that entails positive ${ }^{9}$ monthly cash flows of amount $p_{E} \Delta \epsilon_{f} q_{C_{f}}$ due to the saving of energy costs, Equation (4) computes $P V^{(2)}$, i.e. the present value of these positive cash flows related to the energy savings following the reduced energy intensity value $\epsilon_{f}$ applied to the previous output level $q_{C_{f}}$.

\subsection{Differentiation of banks' capital requirements}

Following the provisions of the Basel capital regulations, bank agents in Eurace are characterized by minimum capital requirements, i.e. by a minimum ratio between equity (net worth) and risk-weighted assets that each bank must satisfy. The rationale for capital requirements is to provide a minimum capital buffer that should be employed to cushion loans or mortgages write-offs and consequent equity losses so to reduce the likelihood of incurring in negative equity and insolvent banks. In particular, in the Eurace model, we state that a bank $b$, when receiving a new loan request from a firm or a new mortgage request from a household, it is allowed to fulfill the request only if its equity base $E_{b}$ is higher than a fraction $\Psi$ of its risk-weighted portfolio of loans and mortgages, including the new prospective loan or mortgage, i.e. only if the following condition holds:

$$
E_{b} \geq \Psi\left(\sum_{i} \omega_{i} a_{i}+\omega_{a^{*}} a^{*}\right)
$$

where $\Psi$ is the capital adequacy ratio, i.e. a policy parameter ranging from 0 to 1 , set by the regulatory authority, $\omega_{i}$ is the risk weight of any existing asset $a_{i}$ (loan or mortgage) of the bank, and $a^{*}$ is the new prospective asset (loan or mortgage) with its risk weight $\omega_{a^{*}}$.

A lower capital adequacy ratio $\Psi$ implies a looser credit regulation policy and a higher likelihood of boom and bust credit cycles with direct effects on the economy. The role of capital requirements for the determination of credit supply and the boom and bust cycles in the Eurace model has been thoughtfully explored, see Cincotti et al. (2012b); Raberto et al. (2012); Teglio et al. (2012). In particular, we performed different computational experiments by

\footnotetext{
$9 \Delta \epsilon_{f}$ shall be considered in absolute terms.
} 
varying the leverage $\alpha$ of the banking system, defined as the inverse of the capital adequacy ratio, i.e. $\alpha=1 / \Psi$, in a setting where credit is characterized by loans to firms only. Our experiments showed that, while loose capital requirements (relatively low $\psi$, i.e. high $\alpha$ ) may induce a credit-driven boom in the short run, the over-levered firms may face at some point ${ }^{10}$ in the future the impossibility to sustain the increasing interest payments with consequent default cascades which are furtherly amplified by the ensuing rationing of bank credit, see Raberto et al. (2012); Teglio et al. (2012). Furthermore, we also explored the potential benefits of a macroprudential approach to banks' capital regulation that would allow varying capital requirements depending on some measures of the business cycle, such as the unemployment, the credit to GDP ratio or the credit growth rate, see Cincotti et al. (2012b).

In the present study, we differentiate the capital adequacy ratio according to the type of credit provided, i.e. loan or mortgage. In particular, if the request received by bank $b$ is for a new loan $\widehat{\ell}_{f}$ by firm $f$, we stipulate that the bank is allowed to grant the loan only if the following relation holds:

$$
E_{b} \geq \Psi_{L}\left(\sum_{i} \omega_{i} a_{i}+\omega_{\widehat{\ell}_{f}} \widehat{\ell}_{f}\right)
$$

whereas in the case there is a request for a mortgage $\widehat{\mu}_{h}$ made by household $h$, then the mortgage is granted only if

$$
E_{b} \geq \Psi_{M}\left(\sum_{i} \omega_{i} a_{i}+\omega_{\widehat{\mu}_{h}} \widehat{\mu}_{h}\right)
$$

where $\sum_{i} \omega_{i} a_{i}$ in both Eq. 6 and 7 is the usual risk weighted portfolio of existing loans and mortgages of the bank and in principle $\Psi_{L} \neq \Psi_{M}$.

In Eq. 6 and 7 we propose a banking regulation that works with two thresholds, depending on the nature of the loan. If $\Psi_{M}$ is higher than $\Psi_{L}$, mortgage loans require a capital adequacy ratio higher than the one required for loans to firms. Therefore, a bank could be in the situation of fulfilling the capital requirements for firms loans but not for mortgages. In particular, when the amount of risky assets of a bank becomes high, thus raising banks leverage, loans are preferred to mortgages and the proposed banking regulation becomes effective.

10 This could be considered what is usually known as Minsky moment, see Minsky (1986). 


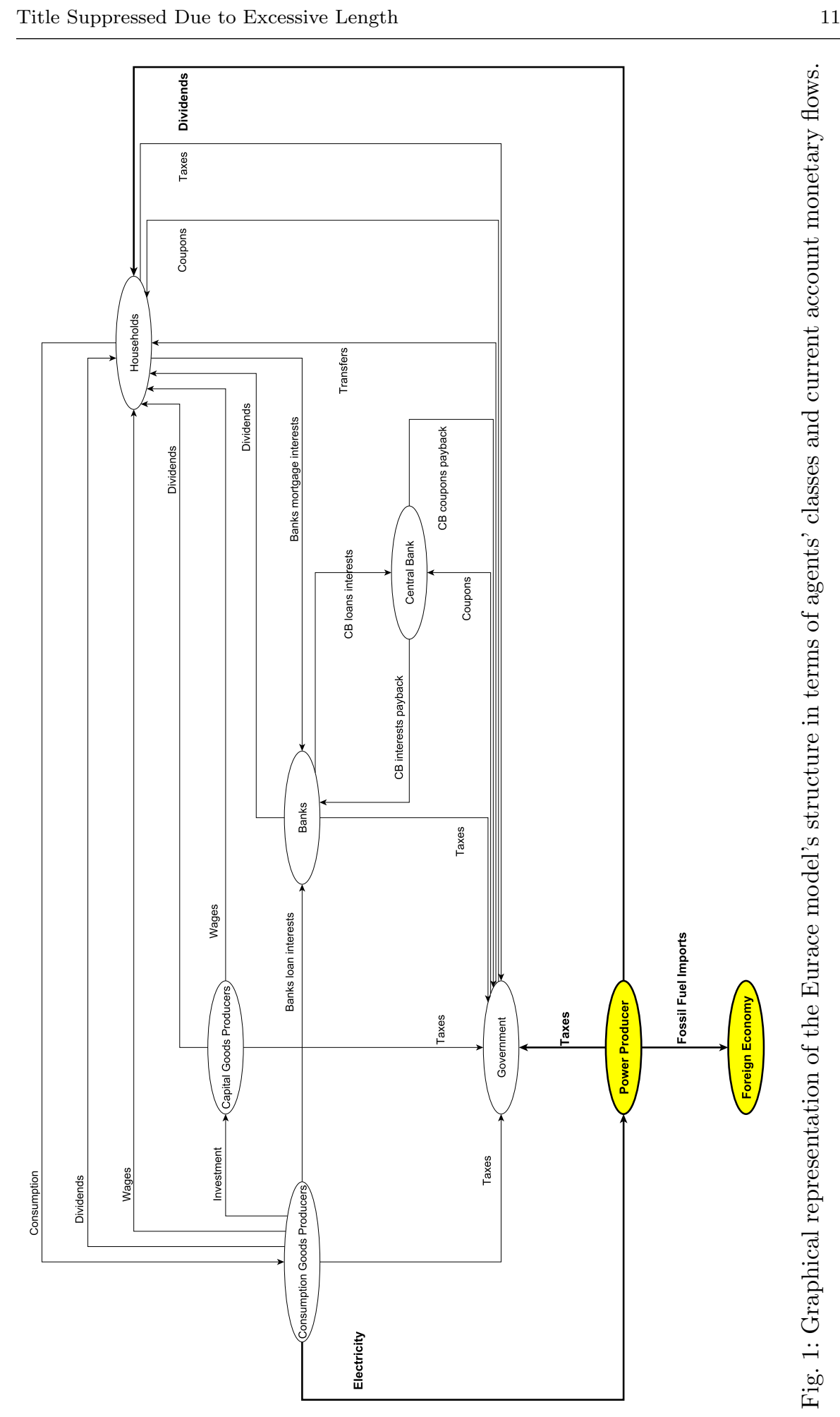




\section{Computational experiments}

A number of computational experiments has been performed in a simulation setting characterized by 3,000 households, 50 consumption goods producers, 3 banks, 1 capital goods producer, 1 power producer, 1 government, and 1 central bank. Table 1 reports the values of the parameters characterizing the housing and the energy sectors. The whole set of parameter values of the model is available in Teglio et al. (2017).

The aim of computational experiments is to assess the impact of differentiating banks' capital requirements based on the type of credit provided, i.e. between mortgages to households for house purchase and loans to firms for productive investments. The rationale behind this choice is the assumption that house purchases are made mostly for speculative purposes and may produce asset bubbles with destabilizing effects, while loans to business firms are aimed to increase their capital endowment with long-run positive effects for the productive capacity of the economy. Banking regulation should then favour lending to business firms with respect to lending for house purchases, e.g. through setting lower capital requirement in the former case. A similar proposal has been set out by Campiglio (2016) to spur green investments, at the expenses of speculative ones, as an alternative to carbon taxation.

To investigate the issue, we have designed a set of computational experiments characterized by capital requirements for mortgages that can be higher or lower than a reference value, i.e. $10 \%$, which is the basic capital requirement value adopted for business loans. In our model design, investments in capital goods provide also an environmental benefit as the new vintages are characterized by higher energy efficiency.

In the following, we use the maximum leverage allowed to banks, henceforth $\alpha$, i.e. the inverse of the capital requirement ratio $\Psi$, to parameterize the computational experiments, as it is more intuitive. In particular, the value of $\alpha$ is set to 10 (the inverse of $10 \%$ ) for all types of loans during the first year of any simulation, while since the second year $\alpha$ is differentiated into a $\alpha_{L}$ for business loans and a $\alpha_{M}$ for mortgages. The maximum allowed leverage $\alpha_{L}$ is then kept at 10 for loans to firms, whereas in the case of mortgages $\alpha_{M}$ is changed to a lower or higher value in the range from 0 to 20 and the new value is maintained for the rest of the simulation. The values assumed by $\alpha_{M}$ are $(0,3,4,5,6,7,8,9,10,11,12,14,17,20)$. It is worth noting that the grid for $\alpha_{M}$ is not equally spaced from 0 to 20 but is more dense around $\alpha_{M}=8$, where indeed we observe the most interesting behavior of the observed economic variables. Furthermore, it should be considered that zero is quite an extreme value that $\alpha_{M}$ can assume, as it means that no more mortgages are granted. For any value of $\alpha_{M}$ considered, 50 different simulations have been performed depending on the seed of the pseudorandom number generator. Figures from 2 to 11 show the distribution of some relevant economic variables for any value of $\alpha_{M}$ considered. In particular, the distributions are represented as boxes which include all the values from the 25 th to the 75 th percentile and with horizontal segments and diamond markers which represent the median and the mean of 
the distribution, respectively. Box-plots also include whiskers extending to the most extreme data points not considered outliers, while outliers are plotted individually.

For every seed (simulation), we consider the time average over two given time periods in order to differentiate a short run and a long run. In this respect, the box-plot figures can be organized into two different groups, where the first group, from Fig. 2 to Fig. 6, reports the time averages from year 2 to year 6 included, i.e. the first 5 years after the differentiation of capital requirements, while the second group, from Fig. 7 to Fig. 11, presents the time averages over the following ten years, i.e. from year 7 to year 16 . The first simulation year has not been considered in the computation of the time averages because in this period $\alpha_{M}$ is not yet differentiated but set to 10 in all cases. To conclude, results have been divided into two periods that can be considered as a short/medium run period for the first 5 years and a long-run period for the following 10 years.

The first time window has been set to five years because this is the time span where the effects of the change of $\alpha_{M}$ are observed to be more relevant and statistically significant on productive investments. In particular, in the panel (a) of Figure 2 we can observe that both the average and the median values of the loans distribution have clearly higher values when $\alpha_{M}$ is lower than 8 . We employ the Wilcoxon rank sum test to verify the null hypothesis that the data reported for different values of $\alpha_{M}$ are taken from distributions with equal medians. If we assume the null hypothesis that the distributions of loans for $\alpha_{M}=(0,3,4)$ have the same medians of the distributions for $\alpha_{M} \geq 6$, this is rejected at the significance level of $5 \%$. Therefore a regulatory action that decreases substantially the maximum allowed leverage (or, equivalently, increases the capital requirements) for speculative investments, here proxied by mortgage debt for house purchase, is effective in diverting credit from speculative to productive investments, at least in the short run (first 5 years). This is also evident when we observe investments and the aggregate capital stock of the economy, panel (b) and (d) of Figure 2, as well as the average energy intensity $\epsilon$, i.e., the amount of required energy for unit of output, panel (c) of the same Figure. The higher pace of investments for low $\alpha_{M}$, because of more credit available, implies newer vintages for firms' capital goods and therefore lower energy intensity on average for the aggregate capital endowment. Panel (b) of Figure 2 shows that the medians of the distribution of the aggregate capital stock in the economy are clearly higher for values of $\alpha_{M}$ lower than 9. In particular, we observe a downward transition of the accumulated capital stock from $\alpha_{M}=4$ to $\alpha_{M}=9$. According to the Wilcoxon rank sum test, the difference is statistically significant at the significance level of $1 \%$. Consistently, we get a lower average energy intensity for lower $\alpha_{M}$, see panel (c) of Figure 2. Also in this case, the difference is statistically significant. It is worth noting that the differences in the main variables of figure 2 are statistically significant in the range of $\alpha_{M}$ from 4 to 9 , confirming that this is a quite critical transition interval. 
Figure 3 presents the main results related to the housing market. In particular, we can observe that, as expected, the aggregate amount of mortgages (panel a) is very sensitive to the value of $\alpha_{M}$ as well as the average housing price (panel b). The looser the banking regulation for mortgages, the higher is the average housing price, therefore increasing the likelihood of credit-driven housing market bubbles and raising the instability of the housing market. In particular, the increase in the average numbers of fire sales in the housing market, as pointed out by panel (c) of Fig. 3, is due to the growing difficulty faced by some households to make mortgage payments. This increases the probability of housing bubble bursts, with possible destabilizing effects on the real economy though the lending channel. Ozel et al. (2016) present a detailed discussion about the effects of credit regulation on the housing market dynamics in Eurace and the possible destabilizing effects of housing bubble busts on the real economy.

Figure 4 presents the effects of the differentiated loan versus mortgage requirements on the real economy. While the medians of the distribution of unemployment rates (panel b) do not exhibit both graphically and statistically significant differences for different values of $\alpha_{M}$, we can clearly observe from panel (c) that GDP growth rates are significantly higher for $\alpha_{M} \geq 8$. For lower values of $\alpha_{M}$, we have observed already higher investment rates, as pointed out by higher levels of loans and capital accumulation showed by panel (a) and (b) of Fig. 2, respectively. The difference in GDP growth rates can be only explained by a even higher difference in the consumption growth rates that should offset the contribution to GDP by higher investment rate at low $\alpha_{M}$. This is actually what we observe in panel (d) of figure 4 . Therefore, the increase of investments rates is realized at the expense of consumption growth rates; but while on the one hand the combined effect looks neutral for unemployment, on the other hand it is not neutral for GDP growth rates, pointing out an important drawback of increasing capital requirements for mortgages. We argue that the explanation of this finding is twofold and concerns both supply and demand side aspects. On the supply side, we understand that fostering investments requires additional labor force employed at the capital goods producer; however, due the internal dynamics of the economy, the overall net result is not a reduction of unemployment but a sort of crowding out effect that diverts the labor force from the consumption goods sector to the capital goods one, see in particular panel (a) and (b) of Fig. 6. On the demand side, we observe that the reduction of mortgages at low $\alpha_{M}$ is not fully compensated by the increase of loans, as the total aggregate credit in the economy, i.e. the sum of mortgages and loans, reported by panel (a) of Fig. 4, exhibits a strong increase for high values of $\alpha_{M}$ similar to the one of mortgages. Our previous studies, see e.g. Raberto et al. (2012); Teglio et al. (2012); Cincotti et al. (2012b), have shown how the level of credit in the economy, i.e. the level of credit money endogenously generated by the banking system, positively affects economic growth, at least in the short term. This happens through the supply side channel, i.e. the availability of resources to firms for investments, as well as through the demand channel, via the higher 
capital income of households, as shareholders of highly profitable banks, and via the higher general money supply which automatically translates to higher nominal demand. Furthermore, both our recent work (Ozel et al. (2016)) and empirical evidence ((ECB, 2013, pag. 21, Chart D)) point out that mortgages seem positively cross-correlated with economic activity and, differently from loans, seem to lead the business cycle.

Figure 5 shows the effects of the policy on prices, i.e., the consumption and the capital goods price level, the nominal wage and the central bank policy rate. The main result is that, while the distribution of capital goods prices is both graphically and statistically independent on the value $\alpha_{M}$, see panel (b), both consumption goods prices (panel a) and nominal wages (panel c) depend on it, yet in an opposite way. It si worth noting that the level of nominal wages in the model depends on the labor market status; in particular, when unemployment is low, firms may face labor shortage and then compete to attract workers by rising their wage offer, see Dawid et al. (2014); Teglio et al. (2017) for more details on the Eurace labor market. The distribution of unemployment rates looks scarcely dependent on $\alpha_{M}$, see panel (a) of Fig. 4; however, the median values of nominal wage does depend on $\alpha_{M}$, see panel (c) of Fig. 5. This evidence can be explained considering that the higher $\alpha_{M}$, the tighter is the labor market competition among CGPs, as shown by the employement rate in the consumption good sector, see panel (a) of Fig. 6; on the other hand, at low $\alpha_{M}$ the competitive effort to attract workers mainly regards the capital good sector, which is characterized by just one single player, differently from the consumption goods sector, where many agents operate.

Interestingly, higher labor costs do not translate into higher consumption goods prices. Indeed, CGPs apply mark-up pricing where unit costs are given by labor costs, energy cost and debt service cost, where the first two costs are variable costs and the latter one is a fixed cost, see Teglio et al. (2017) for more details on the Eurace mark-up pricing. Therefore, higher consumption goods prices are clearly explained by the interests cost of the higher debt burden which CGPs are subject to at lower $\alpha_{M}$ (see panel (a) of figure 2). Higher consumption goods prices combined with lower nominal wages have of course a depressing effect on real wages, as also reported on panel (c) of Fig. 6, thus pointing out another negative consequence of a policy aimed at increasing capital requirements limited to mortgages.

To summarize our findings so far, the strategy of increasing capital requirements for mortgages has proven to be successful in fostering investments and capital accumulation in the short term (five years), and consequently in improving energy efficiency (reducing energy for unit of output) of firms because of the newer vintages of capital goods available. However, these results are achieved at some welfare costs for households which can be summarized in lower consumption growth rates and purchasing power.

The next part of the paper examines if these results are confirmed also in the long run, i.e., in the following 10 years. Figures 7-11 present the distributions as box-plots of the same economic variables presented in figures 2-6, yet 
in a different time period, i.e. from year 7 to year 16, instead of from year 2 to year 6 . Figure 7 shows that while the distribution of energy intensity (panel a) still exhibits both a graphically and statistically significant pattern for different values of $\alpha_{M}$, the distribution of loans, capital stock and investments, are less affected in the long run than in the short run. This means that, during the 10 years period, some counterbalancing force in the economic system is seriously weakening the effects of a regulation which is de facto reducing total mortgage loans (as shown in figure 8). We think that this counterbalancing effect is mainly due to the lower amount of total credit in the economy which in turn reduces the level of endogenous money. In the long run, when $\alpha_{M}$ is decreased in order to limit mortgages, the economy suffers from the demand side. Consumption growth is critically reduced and consumption goods producers have therefore to scale down production and employment. We see that the unemployment rate is increasing in the long run from an average of $2 \%$ to an average close to $8 \%$ when mortgages are hindered. In the first five years, the aggregate credit for low $\alpha_{M}$ values is reduced by a $30 \%$ with respect to high $\alpha_{M}$ values, while in the next ten years the difference grows to $66 \%$, showing that the loss in mortgages and endogenous money accumulates during the years undermining aggregated demand (see Ozel et al. (2016) for further details). Actually, consumption growth rates suffer a $50 \%$ loss in the long run when $\alpha_{M}$ is low, against a $33 \%$ loss in the short run. It is also worth noting that investment decision-making by firms is based on net present value calculations, where expected demand play a crucial role (see Teglio et al. (2017) for further details). This explains to some extent why total loans depend on consumption, and why we do not observe a significant increase of loans when a mortgage-restricting policy is adopted.

Thus, our simulations show that in the long run the effects of a mortgagerestricting policy are mainly negative. For very low values of $\alpha_{M}$ the policy is basically freezing the housing market (see the patterns related to the level of mortgages and the housing price in Fig. 8) with negative outcomes for the real economy, as shown in Fig. 9. For higher values of $\alpha_{M}$ the mortgage markets re-activates, showing of course more instability, characterized by increasing fire sales. In the long term the advantage for lower leverages in term of capital stock accumulation during the short term is no more valid. It still exists an advantage in term of energy efficiency, with an environmental benefit related to energy consumption, however at the price of an increasing welfare costs, which in the long term does not concern only purchasing power and consumption rates but also unemployment rates.

Finally, we performed a robustness check allowing for different fossil fuel price trends. In particular, we considered a constant price trend $\left(\xi_{O}=0\right)$ and a negative monthly exponential growth $\xi_{O}=-0.5 \%$ (downward trend), which are compared with the monthly price growth rate $\xi_{O}=0.5 \%$ (upward trend) that has been used to obtain the previous results.

It is worth noting that the $0.5 \%$ monthly growth rate, i.e. an annual growth rate more than $6 \%$, encompasses the wide range of forecasts about the oil price 
made by relevant international institutions. In particular, the U.S. Energy Information Administration ${ }^{11}$ (EIA) long-term forecasts set the oil price annual growth rate at $3 \%$ in real term and at $5.1 \%$ in nominal term from now to 2050. On the contrary, previsions by the World Bank $^{12}$ up to 2030 are much more conservative and characterized by an annual growth rate of only $2.1 \%$ in nominal term and then by a substantial stability if the oil price is measured in constant US dollars. Finally, the IMF projections ${ }^{13}$, limited to 2018 , point out that the oil price for the year to come should remain stable also in nominal term around 50 USD per barrel. These forecasts are very different from each other, even in the long term, thus highlighting the intrinsic difficulty in correctly predicting future oil price fluctuations, see e.g. Baumeister and Kilian (2016). We therefore think that it would not particularly meaningful to stick to a particular forecast and then to calibrate the system to its value. Actually, agent-based macro-models are fruitfully employed as computational laboratories where to perform what-if analysis about how the economy is affected by a particular hypothesis (e.g. on the annual growth rate of oil price) and how some economic policy will work under the same hypothesis, without any strong claim that this hypothesis will be the one observed in the real world. According with this perspective we have considered the highest value, among the official forecasts examined, for the growth rate of oil price and we have then performed additional computational experiments considering both a constant price and a decreasing trend for fossil fuels. The main outcomes, collected in figures 12 and 13, show that all the essential results of the paper are confirmed, and that the impact of the "green capital requirements differentiation" policy does not depend on the price trend of fossil fuel. The box-plot have been organized in two figures. Figure 12 reports the time averages from year 2 to year 6 included, i.e. the first 5 years after the differentiation of capital requirements, while figure 13 presents the time averages over the following ten years, i.e. from year 7 to year 16 .

Figure 12 clearly shows how inflation of fossil fuel price affects directly the level of consumption goods prices. In turn, the level of prices affects all the nominal values of the economic indicators. For example, we note that the amount of nominal loans raises with the price. We can also note that loans are increasing with "green incentives" (low $\alpha_{M}$ ) in the three considered cases. The same holds for the accumulation of firms' capital stock, which is always higher when "green incentives" are stronger. Therefore, the main result on the energy intensity is also confirmed. The higher capital stock level (the plot represents real units of capital stock) for higher fossil fuel prices can be explained by two main arguments. From the supply side, "green incentives" favor loans to enterprises over mortgages, as previously discussed, decreasing firms' chance to be rationed in the credit market and therefore raising the probability to carry

\footnotetext{
11 https://www.eia.gov/outlooks/aeo/pdf/appa.pdf

12 http://pubdocs.worldbank.org/en/678421508960789762/CMO-October-2017Forecasts.pdf

13 https://www.imf.org/en/Publications/WEO/Issues/2017/09/19///media/Files/Publications/WEO/2017/October/pdf/mainchapter/tblparta.ashx
} 
out investments successfully. From the demand side, the higher inflation in consumption price, driven by fossil fuel price inflation, increases the expected nominal profits and leads to a higher demand for capital goods and loans.

The other main results of the paper are also confirmed. For instance we see in figure 12 an employment shift from consumption goods producers to capital goods producers when $\alpha_{M}$ decreases. This result is due to the higher activity of the KGP, and is not altered by different price trends.

Concerning the long run outcomes of the simulations, what has been observed in the paper is still valid. The housing market freezing for low $\alpha_{M}$, causes a credit contraction that finally affects employment and economic activity. In figure 13 both the credit contraction and the higher unemployment rate are visible.

\section{Concluding remarks}

Inspired by some recent proposals, aiming at promoting green investments at the expenses of speculative ones, we designed a set of computational experiments within the agent-based model Eurace. We devised a simple regulation for banks in order to incentivize loans to firms with respect to real estate mortgage lending. The regulation consists in demanding higher capital requirements for banks in the case of mortgages, thus encouraging banks to give loans to firms. As up-to-date capital goods have better energy efficiency in the model design, a higher pace of investments implies also lower energy intensity per unit of produced consumption goods, then energy savings and a positive environmental externality. Simulations outcomes suggest that the regulation is successful in promoting investments and capital accumulation in the short term, and consequently in improving energy efficiency of firms. However, these results are achieved at some welfare costs for households which can be summarized in lower consumption growth rates and purchasing power. The reason is that reducing mortgages with a restrictive regulation has a negative impact on the total private credit in the economy, and therefore on the endogenous money supply. This, in turn, reduces consumption and aggregate demand.

In the long term, the contraction of total credit increases, and the negative outcomes on aggregate demand become more serious, reducing also firms investments. Therefore, in the long run, the positive effects on capital and energy efficiency become negligible, while the main economic indicators show a period of recession.

Furthermore, in line with previous experiments, our model shows the important role of endogenous money in the economy. Mortgages and loans represent the crucial way to channel money to households, and if they are hindered all the economy suffers, reaching higher unemployment rates. Besides, the model has also shown that a loose regulation of mortgages can lead to instability in the housing market with negative repercussion on the real economy. This means that a fine tuned regulation, that keeps into account the business 
cycle dynamics is probably needed. Our next step will be to implement this fine tuning, considering macro-prudential rules, or more sophisticated regulations with the goal to foster green investments on the one hand, and to provide enough credit to sustain the performance of the economy on the other hand.

Furthermore, it is worth discussing the scope and the limitations of our study. To the best of our knowledge, this is the first attempt to validate through computational experiments a recently proposed banking regulatory framework (Campiglio (2016)) aimed to foster green investments. An agentbased macroeconomic model environment, where endogenous money created by the banking system plays a crucial role in determining economic dynamics, has been employed for this purpose. Important simplifying assumptions that may limit the validity of our results have been made. In particular, we assume an exogenously given technological progress that grows the energy efficiency of capital goods. This assumption has been quite common among the seminal contributions in climate change economics, see e.g. Nordhaus (1994); Nordhaus and Boyer (2000); Stern (2009), which have been mostly focused on computable general equilibrium models with exogenous technology. More recently, Acemoglu et al. (2012, 2016), building on pioneering work on the interaction between endogenous innovation and environmental policies, see e.g. van der Zwaan et al. (2002); Popp (2004), introduce a comprehensive growth model with environmental constraints characterized by endogenous and directed technical change, showing among other things that models characterized by exogenously-given technological progress overstate the economic costs of environmental regulation. The overestimation of environmental policy costs, which in our setting can be identified as the observed long-run growth gap in the case of strict bank capital regulation for mortgage lending, may in principle occur also in our model, where technological progress is exogenously given. However, it is worth remarking that the Acemoglu et al' model is very different with respect to the model discussed in this paper, both in term of modelling approach (general equilibrium versus out-of-equilibrium dynamics) and policy instrument (carbon tax and research subsidies versus banking regulation); therefore, we argue that this problem is not necessarily present in our analysis. Furthermore, we point out that while the energy efficiency of up-to-date capital goods is exogenously given, the average energy efficiency of each consumption goods producer is path dependent and endogenously determined by its investment choices, therefore our model construction takes into account at the level of the single firm the path dependency of technological endowment, as in the Acemoglu et al' model. In any case, future model developments will address the issue of endogenous technological change.

Finally, while the policies investigated by Acemoglu et al. can be considered as market-based policies, i.e. characterized by monetary incentives and price signals, the bank capital adequacy ratio policy employed in our experiments can be classified among the command-and-control policies, i.e. based on the setting of quotas and quantity thresholds. Many studies have compared the effects of market-based and command-and-control policies, see e.g. Hepburn (2006); Goulder and Parry (2008) for extensive comparisons. Recently, Lam- 
perti et al. (2015) building of the model by Acemoglu et al. (2012) showed that command-and-control interventions guarantee policy effectiveness irrespectively of the timing of their intervention, differently from market-based ones which instead are characterized by bounded window of opportunity.

Our future research will surely investigate the effectiveness of a carbon tax in fostering capital goods investments by firms to raise their average energy efficiency and will compare the results with the command-and-control policy adopted in this study.

\section{Acknowledgments}

The authors acknowledge EU-FP7 collaborative project SYMPHONY under grant no. 611875 .

\section{Compliance with Ethical Standards}

This study was funded by EU-FP7 (grant number 611875). The authors declare that they have no conflict of interest.

\section{References}

Acemoglu, D., Aghion, P., Bursztyn, L., Hemous, D., February 2012. The environment and directed technical change. American Economic Review 102 (1), $131-66$

URL http://www . aeaweb.org/articles?id=10.1257/aer.102.1.131

Acemoglu, D., Akcigit, U., Hanley, D., Kerr, W., 2016. Transition to clean technology. Journal of Political Economy 124 (1), 52-104.

Aglietta, M., Espagne, E., Perrissin-Fabert, B., 2015. A proposal to finance low carbon investment in europe. France Stratégie: Paris.

Arthur, W. B., 2006. Out-of-equilibrium economics and agent-based modeling. Handbook of computational economics 2, 1551-1564.

Assenza, T., Delli Gatti, D., Grazzini, J., 2015. Emergent dynamics of a macroeconomic agent based model with capital and credit. Journal of Economic Dynamics and Control 50, 5- 28.

Baker, D., 2008. The housing bubble and the financial crisis. Real-world economics review 46 (20), 73-81.

Balint, T., Lamperti, F., Mandel, A., Napoletano, M., Roventini, A., Sapio, A., 2017. Complexity and the economics of climate change: a survey and a look forward. Ecologial Economics 138, 252-265.

Baumeister, C., Kilian, L., 2016. Forty years of oil price fluctuations: why the price of oil may still surprise us. Journal of Economic Perspectives, 30 (1), 139-160.

Bernanke, B., Gertler, M., 1989. Agency costs, net worth, and business fluctuations. The American Economic Review, 14-31. 
Caiani, A., Godin, A., Caverzasi, E., Gallegati, M., Kinsella, S., Stiglitz, J. E., 2015. Agent based-stock flow consistent macroeconomics: Towards a benchmark model. Available at SSRN.

URL http://dx.doi.org/10.2139/ssrn. 2664125

Campiglio, E., 2016. Beyond carbon pricing: The role of banking and monetary policy in financing the transition to a low-carbon economy. Ecological Economics 121, 220-230.

Caverzasi, E., Godin, A., 2015. Post-keynesian stock-flow-consistent modelling: a survey. Cambridge Journal of Economics 39 (1), 157-187.

Cincotti, S., Raberto, M., Teglio, A., 2010. Credit money and macroeconomic instability in the agent-based model and simulator eurace. Economics: The Open-Access, Open-Assessment E-Journal 4 (2010-26).

Cincotti, S., Raberto, M., Teglio, A., 2012a. The Eurace macroeconomic model and simulator. In: Agent-based Dynamics, Norms, and Corporate Governance. The proceedings of the 16-th World Congress of the International Economic Association. Vol. II. Palgrave.

Cincotti, S., Raberto, M., Teglio, A., 2012b. Macroprudential policies in an agent-based artificial economy. Agent-based Models and Economy Policy, 205-234.

Dawid, H., Gemkow, S., Harting, P., Van der Hoog, S., Neugart, M., 2016. Agent-based macroeconomic modeling and policy analysis: The eurace@unibi model. In: Chen, S.-H., Kaboudan, M. (Eds.), Handbook of Computational Economics and Finance. Oxford University Press, Oxford.

Dawid, H., Harting, P., Neugart, M., 2014. Economic convergence: Policy implications from a heterogeneous agent model. Journal of Economic Dynamics and Control 44, $54-80$.

Dosi, G., Fagiolo, G., Napoletano, M., Roventini, A., 2013. Income distribution, credit and fiscal policies in an agent-based Keynesian model. Journal of Economic Dynamics \& Control 37 (8), 1598-1625.

Dosi, G., Fagiolo, G., Napoletano, M., Roventini, A., Treibich, T., 2015. Fiscal and monetary policies in complex evolving economies. Journal of Economic Dynamics and Control 52, $166-189$.

Dosi, G., Fagiolo, G., Roventini, A., September 2010. Schumpeter meeting keynes: A policy-friendly model of endogenous growth and business cycles. Journal of Economic Dynamics and Control 34 (9), 1748-1767.

Duca, J. V., Muellbauer, J., Murphy, A., 2010. Housing markets and the financial crisis of 2007-2009: lessons for the future. Journal of financial stability 6 (4), 203-217.

ECB, 2013. Monthly Bulletin October. URL https://www.ecb.europa.eu/pub/pdf/mobu/mb201310en.pdf

Erlingsson, E., Teglio, A., Cincotti, S., Stefansson, H., Sturluson, J., Raberto, M., 2014. Housing market bubbles and business cycles in an agent-based credit economy. Economics: The Open-Access, Open-Assessment E-Journal 8 (2014-8).

Fagiolo, G., Roventini, A., 2016. Macroeconomic policy in dsge and agentbased models redux: New developments and challenges ahead. Available at 
SSRN.

URL http://dx.doi.org/10.2139/ssrn.2763735

Farmer, J. D., Hepburn, C., Mealy, P., Teytelboym, A., 2015. A third wave in the economics of climate change. Environmental and Resource Economics 62 (2), 329-357.

Ferron, C., Morel, R., 2014. Smart unconventional monetary (sumo) policies: Giving impetus to green investment. Climate Report 46.

Gerst, M. D., Wang, P., Roventini, A., Fagiolo, G., Dosi, G., Howarth, R. B., Borsuk, M. E., 2013. Agent-based modeling of climate policy: An introduction to the engage multi-level model framework. Environmental modelling \& software 44, 62-75.

Godley, W., Lavoie, M., 2012. Monetary Economics: An Integrated Approach to Credit, Money, Income, Production and Wealth, 2nd Edition. Palgrave Macmillan.

Goulder, L. H., Parry, I. W., 2008. Instrument choice in environmental policy. Review of environmental economics and policy 2 (2), 152-174.

Gualdi, S., Tarzia, M., Zamponi, F., Bouchaud, J., 2015. Tipping points in macroeconomic agent-based models. Journal of Economic Dynamics and Control 50, $29-61$.

Hepburn, C., 2006. Regulation by prices, quantities, or both: a review of instrument choice. Oxford review of economic policy 22 (2), 226-247.

IEA, 2012. Energy technology perspectives 2012: pathways to a clean energy system. OECD/IEA.

IEA, 2016. Energy Efficiency Market Report 2016. OECD/IEA.

Kaldor, N., 1972. The irrelevance of equilibrium economics. The Economic Journal 82, 1237-1255.

Keen, S., et al., 2009. The global financial crisis, credit crunches and deleveraging. Journal of Australian Political Economy, The (64), 22.

Kiyotaki, N., Moore, J., 1997. Credit cycles. Journal of political economy 105 (2), 211-248.

Klimek, P., Poledna, S., Farmer, D., Thurner, S., 2015. To bail-out or to bailin? answers from an agent-based model. Journal of Economic Dynamics and Control 50, $144-154$.

Lamperti, F., Napoletano, M., Roventini, A., 2015. Preventing environmental disasters: Market-based vs. commandand-control policies. LEM Papers Series 2015/34.

McLeay, M., Radia, A., Thomas, R., 2014. Money creation in the modern economy. Bank of England Quarterly Bulletin 54 (1), 14-27.

Minsky, H., 1986. Stabilizing an Unstable Economy. Yale University Press.

Monasterolo, I., Raberto, M., 2018. The EIRIN flow-of-funds behavioural model of green fiscal policies and green sovereign bonds. Ecological Economics 144 (2), 228-243.

Muellbauer, J., 2015. Housing and the macroeconomy: inflation and the financial accelerator. Journal of Money, Credit and Banking 47 (S1), 51-58.

Nelson, D., Shrimali, G., 2014. Finance mechanisms for lowering the cost of renewable energy in rapidly developing countries. Climate Policy Initiative. 
Nordhaus, W. D., 1994. Managing the global commons: the economics of climate change. Vol. 31. MIT press Cambridge, MA.

Nordhaus, W. D., 2013. The climate casino: Risk, uncertainty, and economics for a warming world. Yale University Press.

Nordhaus, W. D., Boyer, J., 2000. Warming the world: economic models of global warming. MIT press.

Ozel, B., Nathanael, R. C., Raberto, M., Teglio, A., Cincotti, S., 2016. Macroeconomic implications of mortgage loans requirements: an agent based approach. Working Papers 2016/05, Economics Department, Universitat Jaume I, Castelln (Spain).

Ponta, L., Raberto, M., Teglio, A., Cincotti, S., 2018. An agent-based stockflow consistent model of the sustainable transition in the energy sector. Ecological Economics 145, 274-300.

Popp, D., 2004. Entice: endogenous technological change in the dice model of global warming. Journal of Environmental Economics and management 48 (1), 742-768.

Raberto, M., Cincotti, S., Teglio, A., 2014. Economic Policy and the Financial Crisis. Routledge Frontiers of Political Economy. Taylor \& Francis, Ch. 9.

Raberto, M., Teglio, A., Cincotti, S., 2012. Debt deleveraging and business cycles. an agent-based persperctive. The Open-Access, Open-Assessment EJournal 6, 2012-27.

Riccetti, L., Russo, A., Gallegati, M., 2015. An agent based decentralized matching macroeconomic model. Journal of Economic Interaction and Coordination 10 (2), 305-332.

Rozenberg, J., Hallegatte, S., Perrissin-Fabert, B., Hourcade, J.-C., 2013. Funding low-carbon investments in the absence of a carbon tax. Climate Policy 13 (1), 134-141.

Ruiz, J. R., Stupariu, P., Vilariño, Á., 2015. The crisis of spanish savings banks. Cambridge Journal of Economics, bev078.

Russo, A., Riccetti, L., Gallegati, M., 2016. Increasing inequality, consumer credit and financial fragility in an agent based macroeconomic model. Journal of Evolutionary Economics 26 (1), 25-47.

Stern, N., 2009. A Blueprint for a Safer Planet: How to Manage Climate Change and Create a New Era of Progress and Prosperity. London: Bodley Head.

Teglio, A., Mazzocchetti, A., Ponta, L., Raberto, M., Cincotti, S., 2017 (forthcoming). Budgetary rigour with stimulus in lean times: Policy advices from an agent-based model. Journal of Economic Behavior and Organization. https://doi.org/10.1016/j.jebo.2017.09.016

Teglio, A., Raberto, M., Cincotti, S., 2012. The impact of banks' capital adequacy regulation on the economic system: An agent-based approach. Advances in Complex Systems 15 (supp02), 1250040.

Tonelli, F., Fadiran, G., Raberto, M., Cincotti, S., 2016. Approaching industrial sustainability investments in resource efficiency through agent-based simulation. In: Borangiu, T., Trentesaux, D., Thomas, A., McFarlane, D. (Eds.), Service Orientation in Holonic and Multi-Agent Manufacturing. 
Springer, pp. 145-155.

Turner, A., 2013. Debt, money and mephistopheles: How do we get out of this mess? Speech by Adair Turner, FSA Executive Chairman at the Cass Business School.

UNEP, 2016. Global trends in renewable energy investment 2016. UNEP Report.

van der Zwaan, B. C., Gerlagh, R., Schrattenholzer, L., et al., 2002. Endogenous technological change in climate change modelling. Energy economics 24 (1), 1-19.

WB, 2015. State and trends of carbon pricing 2015. World Bank Publications. WEF, 2013. The green investment report: The ways and means to unlock private finance for green growth,(geneva, switzerland: World economic forum).

Werner, R. A., 2014. Can banks individually create money out of nothing?the theories and the empirical evidence. International Review of Financial Analysis $36,1-19$.

Xiao, Q., Devaney, S., 2016. Are mortgage lenders guilty of the housing bubble? a uk perspective. Applied Economics 48 (45), 4271-4290. 


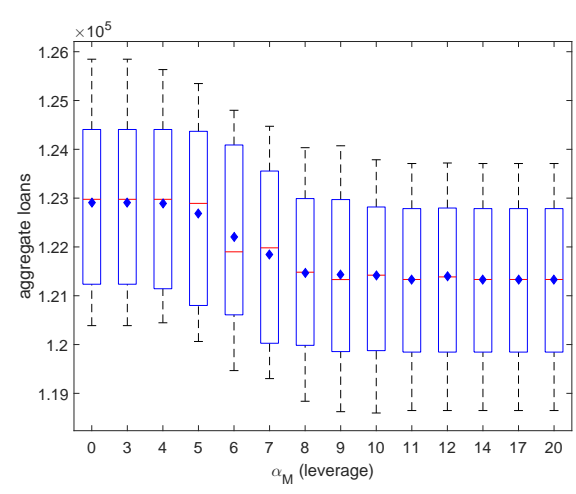

(a)

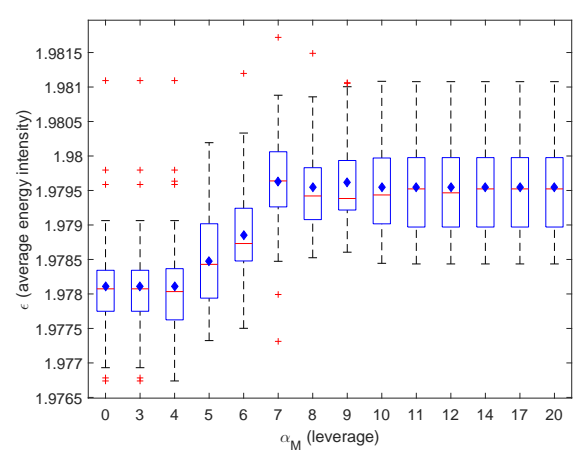

(c)

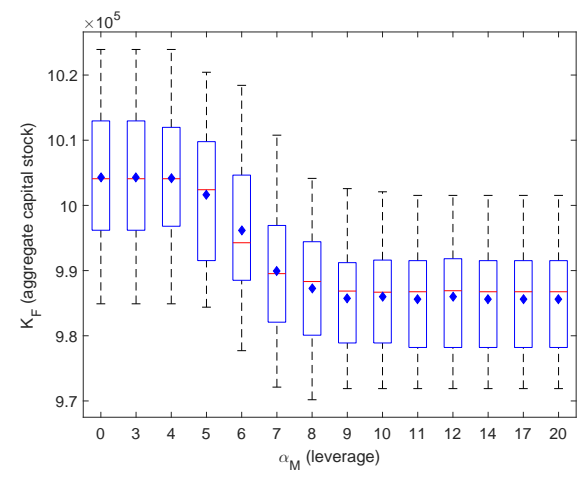

(b)

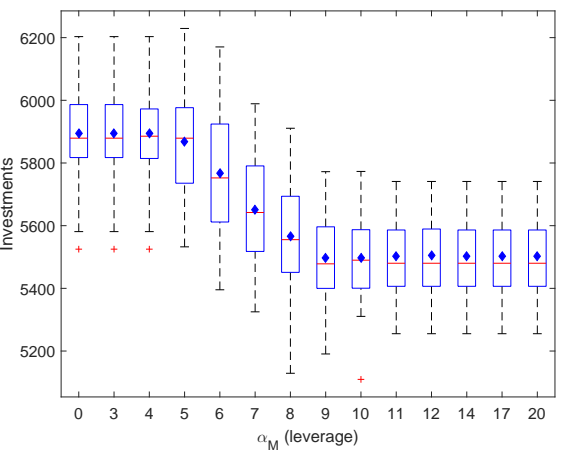

(d)

Fig. 2: The four panels represent aggregate loans (a), aggregate capital stock (b), average energy intensity (c) and aggregate investments (d), respectively. The boxplots report for each value of $\alpha_{M}$ considered the time averages from year 2 to year 6 for any of the 50 seeds (simulations). As for energy intensity and capital stock, we report the value at year 6 instead of the time average along the five years period. 


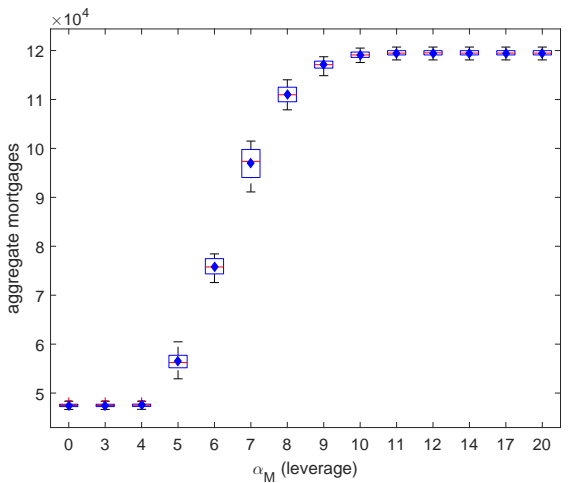

(a)

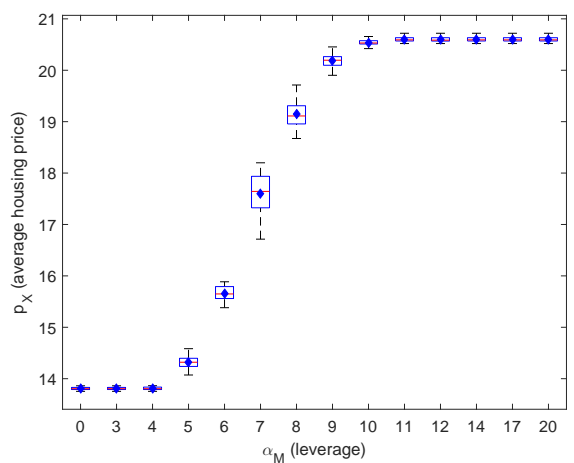

(b)

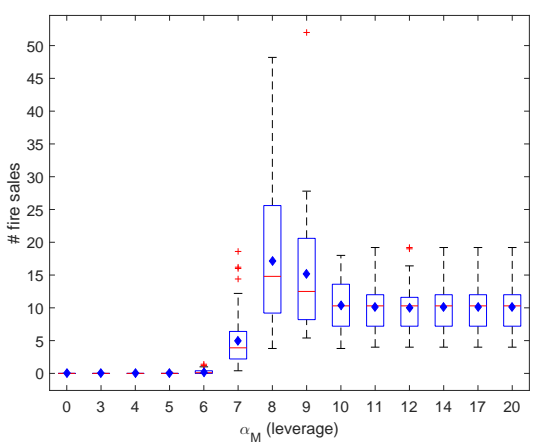

(c)

Fig. 3: The three panels represent aggregate mortgages (a), average housing price (b), and the number of average fire sales (c), respectively. The boxplots report for each value of $\alpha_{M}$ considered the time averages from year 2 to year 6 for any of the 50 seeds (simulations). 


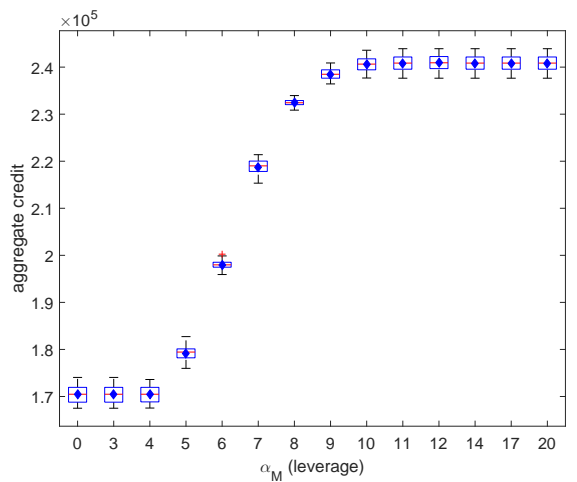

(a)

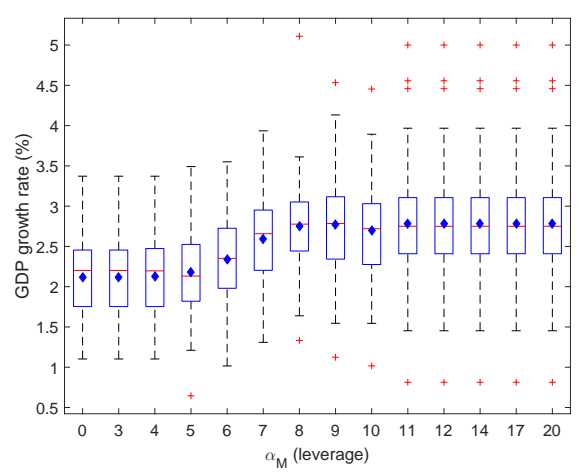

(c)

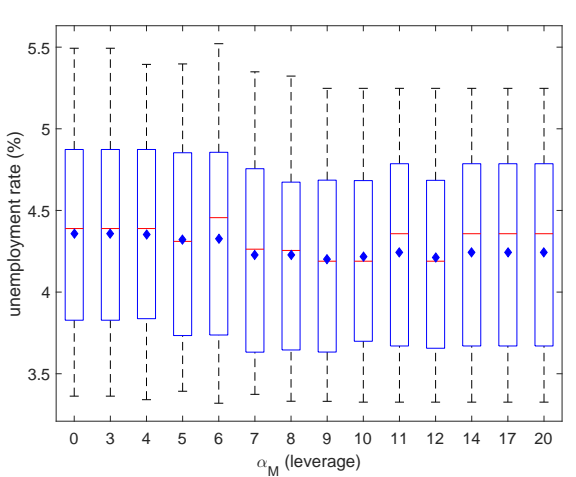

(b)

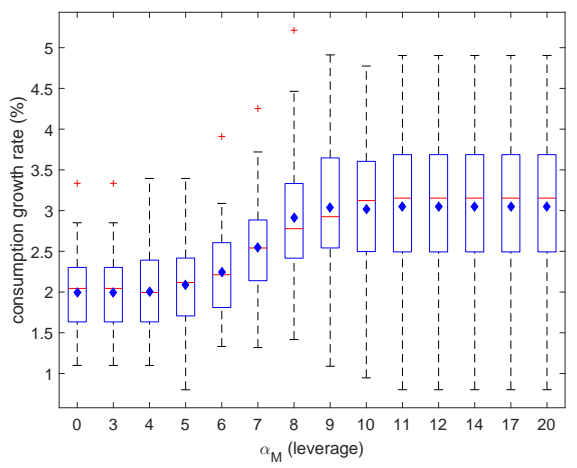

(d)

Fig. 4: The four panels represent total credit (loans + mortgages) (a), the unemployment rate (b), the real GDP growth rate (c) and the real consumption growth rate $(\mathrm{d})$, respectively. The boxplots report for each value of $\alpha_{M}$ considered the time averages from year 2 to year 6 for any of the 50 seeds (simulations). 


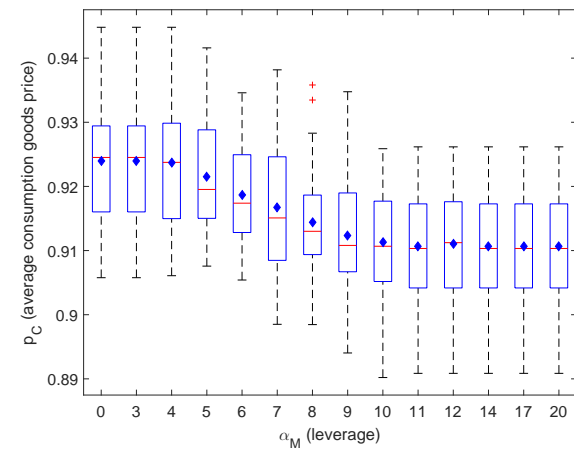

(a)

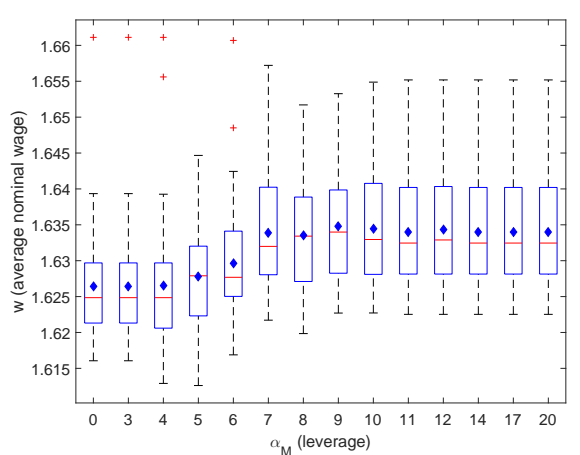

(c)

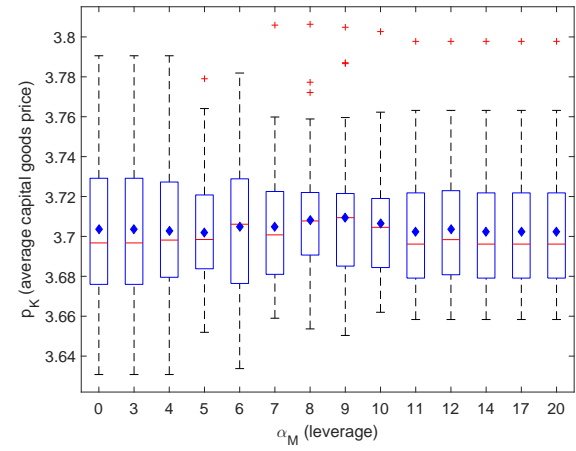

(b)

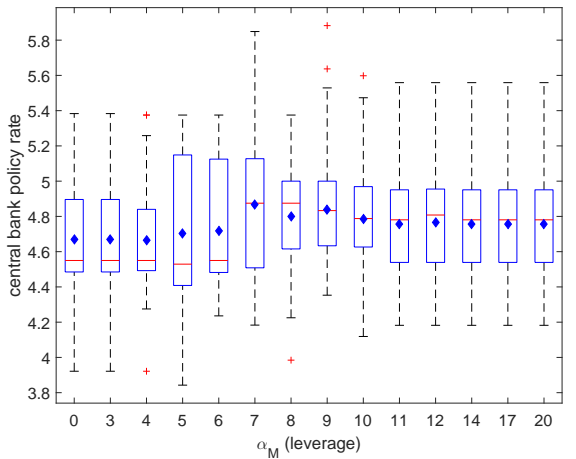

(d)

Fig. 5: The four panels represent consumption goods price level (a), capital goods price level (b), nominal wage level (c) and central bank interest rate (d), respectively. The boxplots report for each value of $\alpha_{M}$ considered the time averages from year 2 to year 6 for any of the 50 seeds (simulations). 


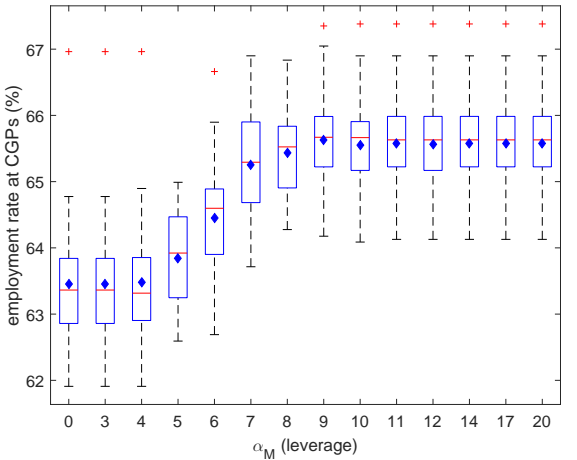

(a)

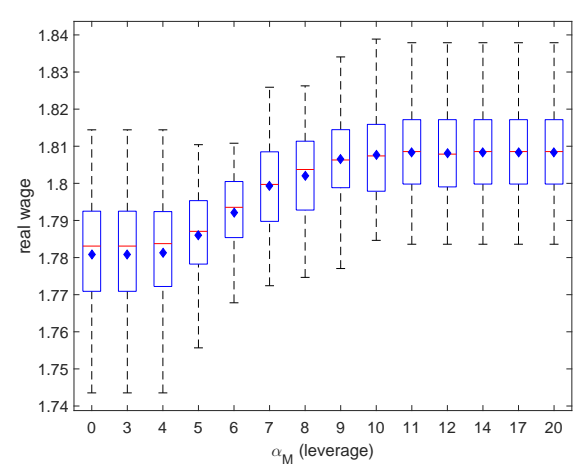

(c)

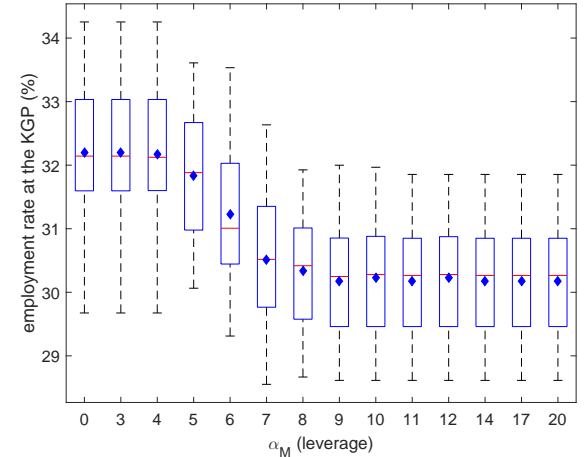

(b)

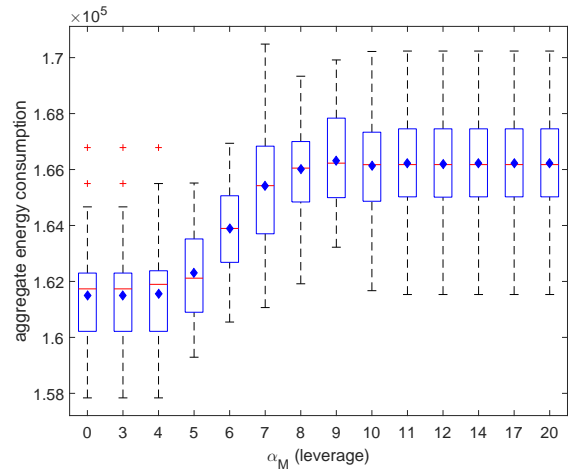

(d)

Fig. 6: The four panels represent the employment rate in the consumption goods sector (a), the employment rate in the capital goods sector (b), the real wage level (c) and the aggregate energy consumption (d), respectively. The boxplots report for each value of $\alpha_{M}$ considered the time averages from year 2 to year 6 for any of the 50 seeds (simulations). 


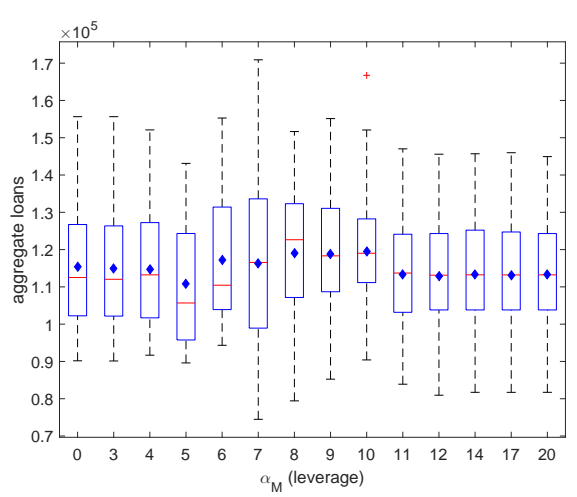

(a)

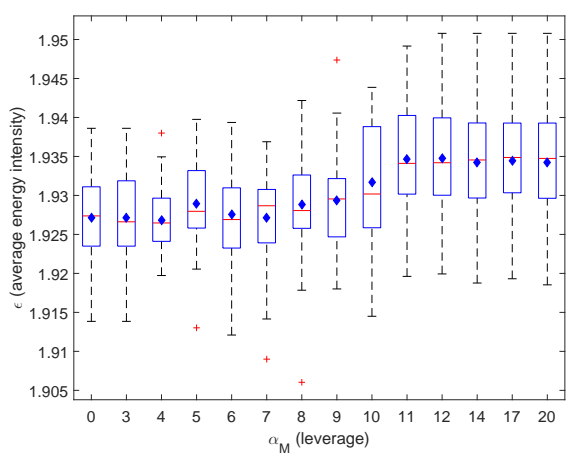

(c)

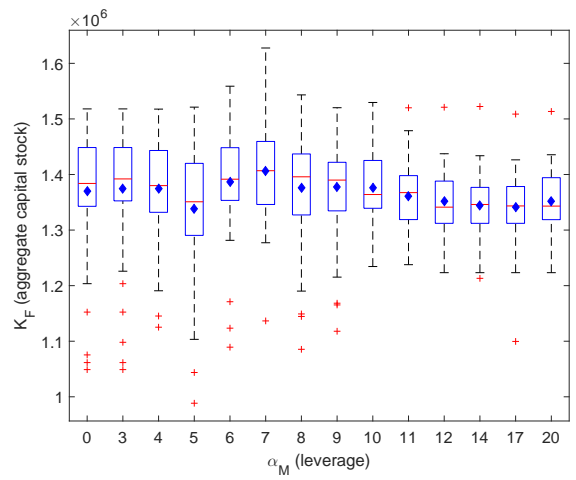

(b)

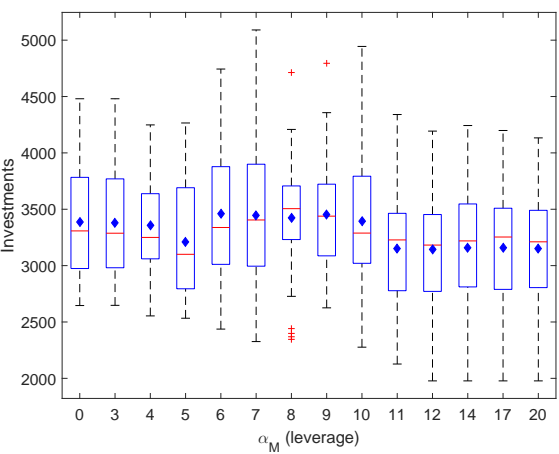

(d)

Fig. 7: The four panels represent aggregate loans (a), aggregate capital stock (b), average energy intensity (c) and aggregate investments (d), respectively. The boxplots report for each value of $\alpha_{M}$ considered the time averages from year 7 to year 16 for any of the 50 seeds (simulations). As for energy intensity and capital stock, we report the value at year 16 instead of the time average along the ten years period. 


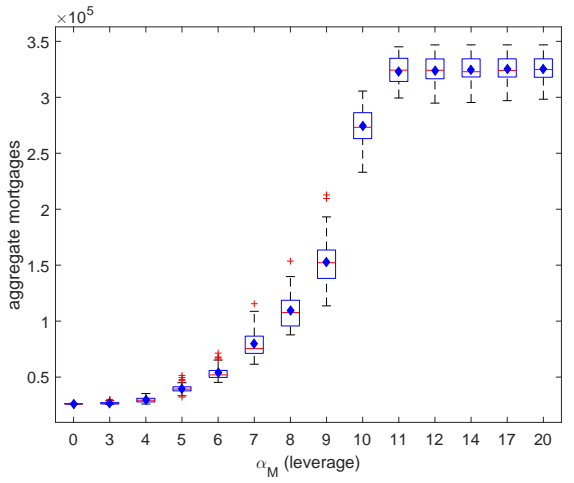

(a)

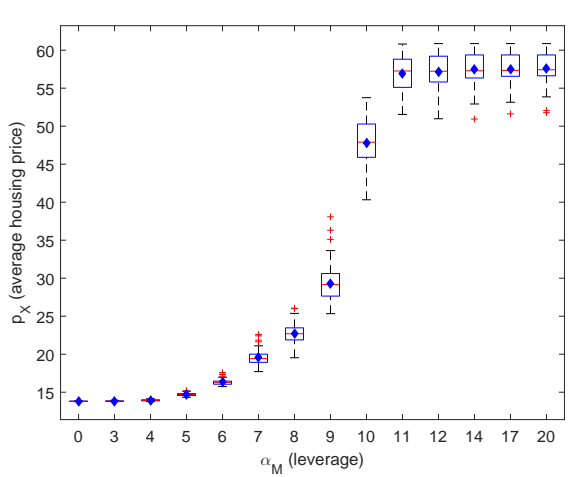

(b)

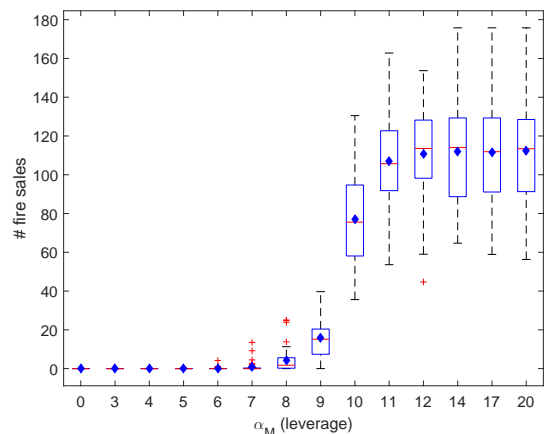

(c)

Fig. 8: The three panels represent aggregate aggregate mortgages (a), average housing price (b), and the number of average fire sales (c), respectively. The boxplots report for each value of $\alpha_{M}$ considered the time averages from year 7 to year 16 for any of the 50 seeds (simulations). 


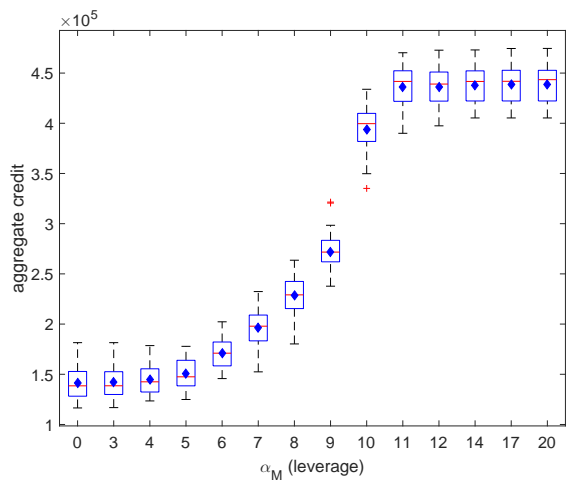

(a)

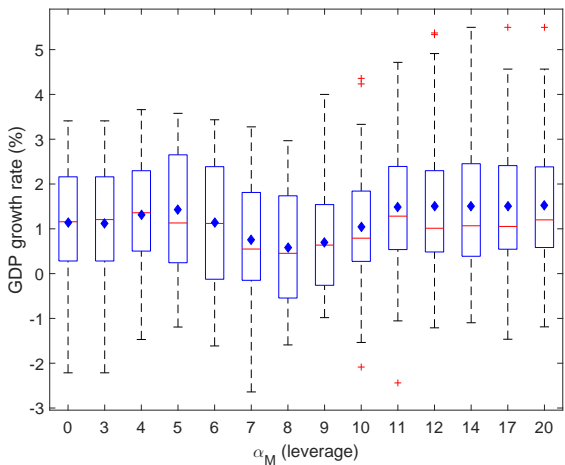

(c)

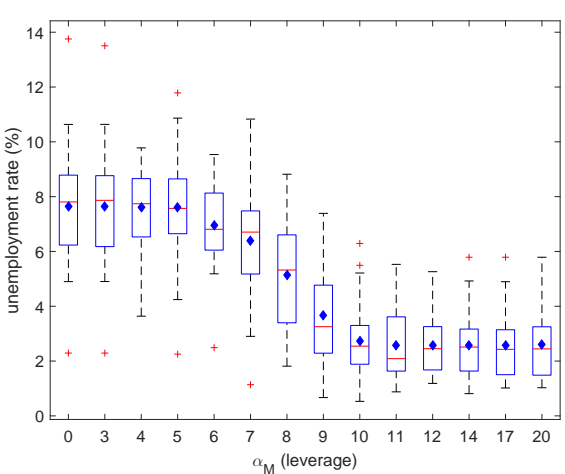

(b)

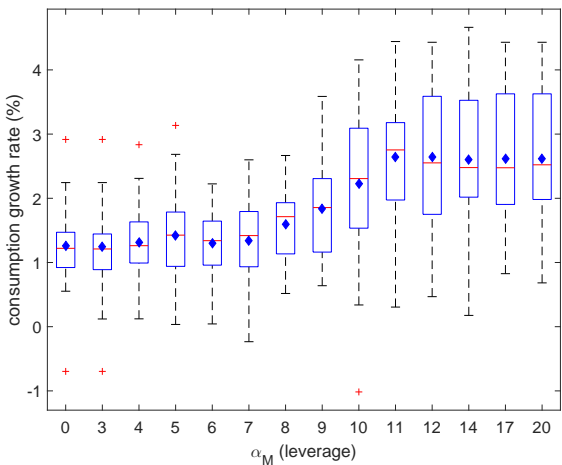

(d)

Fig. 9: The four panels represent total credit (loans + mortgages) (a), the unemployment rate (b), the real GDP growth rate (c) and the real consumption growth rate (d), respectively. The boxplots report for each value of $\alpha_{M}$ considered the time averages from year 7 to year 16 for any of the 50 seeds (simulations). 


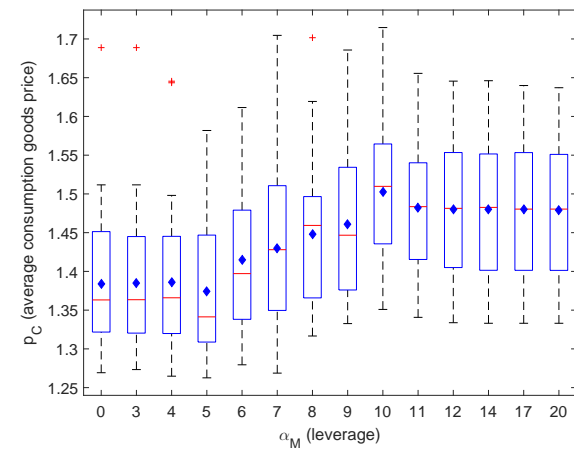

(a)

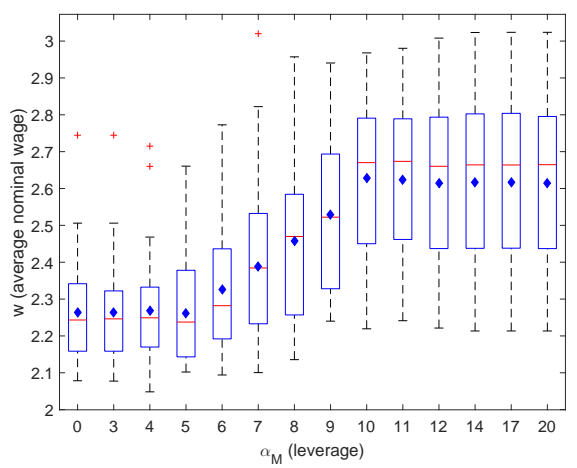

(c)

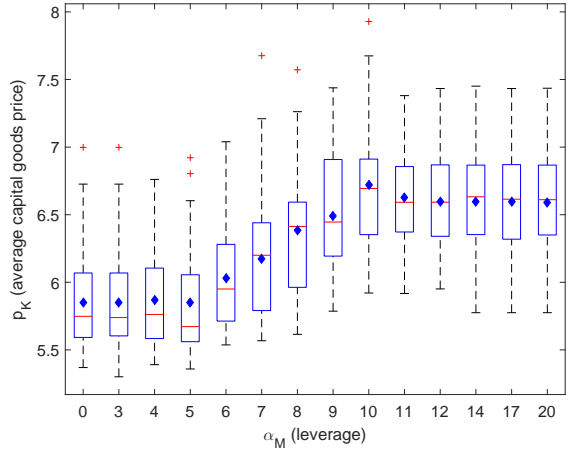

(b)

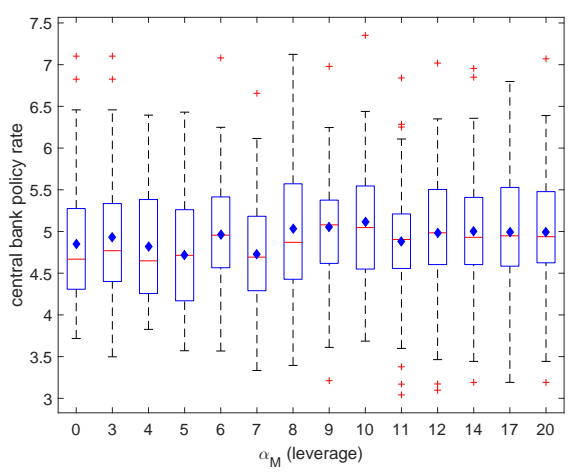

(d)

Fig. 10: The four panels represent consumption goods price level (a), capital goods price level (b), nominal wage level (c) and central bank interest rate (d), respectively. The boxplots report for each value of $\alpha_{M}$ considered the time averages from year 7 to year 16 for any of the 50 seeds (simulations). 


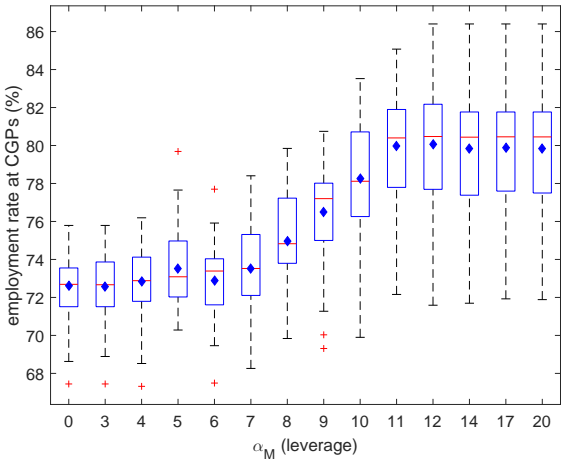

(a)

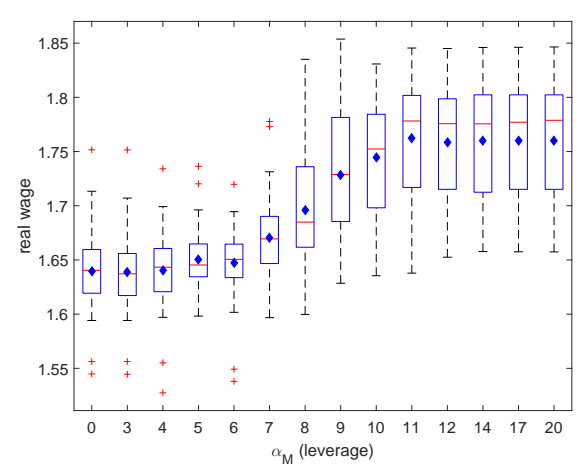

(c)

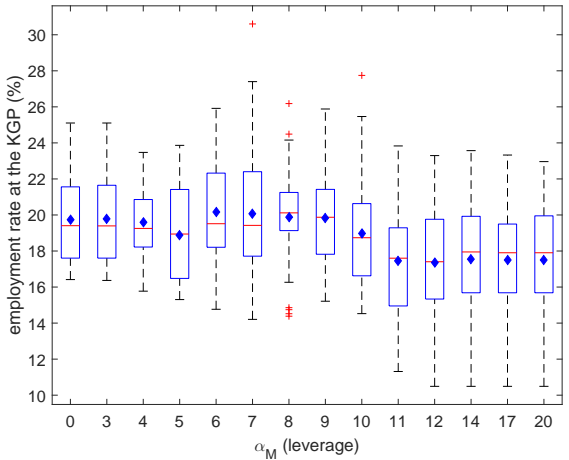

(b)

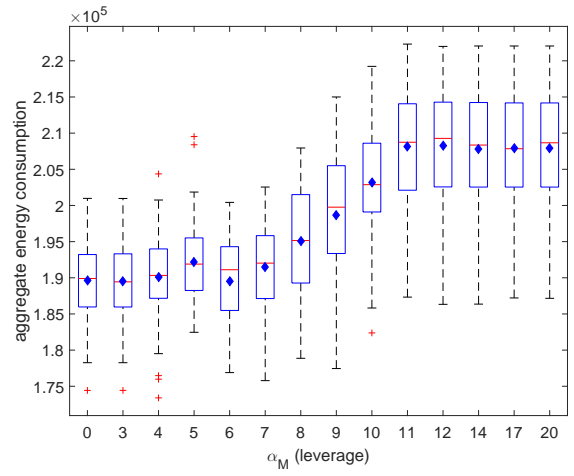

(d)

Fig. 11: The four panels represent the employment rate in the consumption goods sector (a), the employment rate in the capital goods sector (b), the real wage level (c) and the aggregate energy consumption (d), respectively. The boxplots report for each value of $\alpha_{M}$ considered the time averages from year 7 to year 16 for any of the 50 seeds (simulations). 


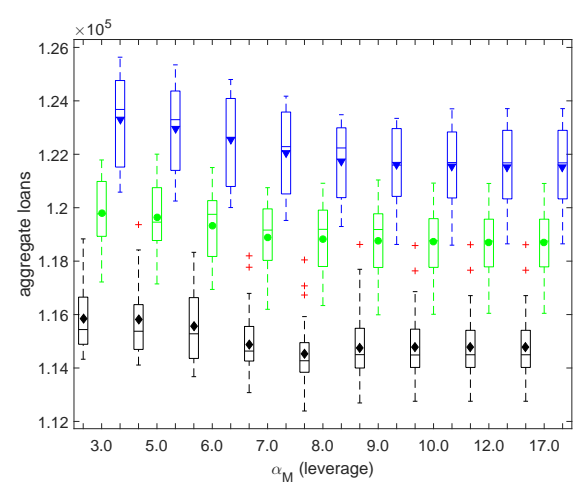

(a)

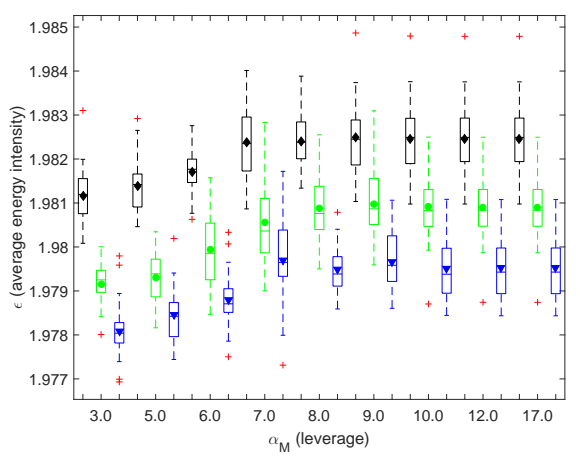

(c)

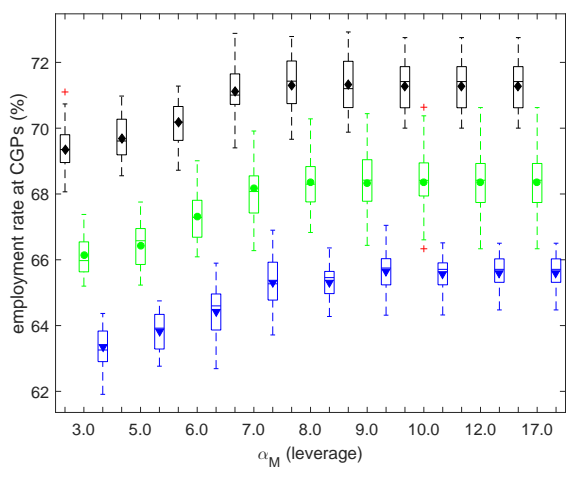

(e)

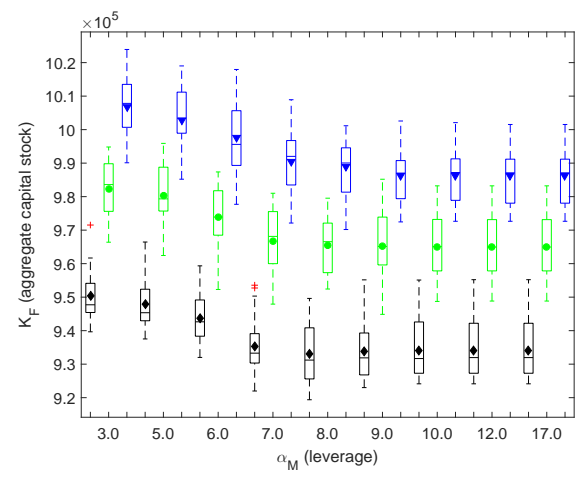

(b)

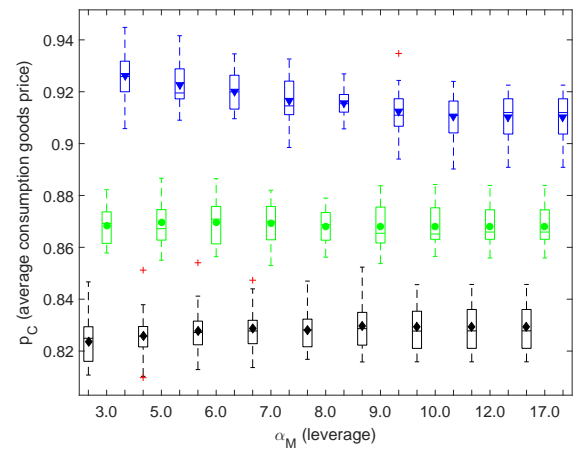

(d)

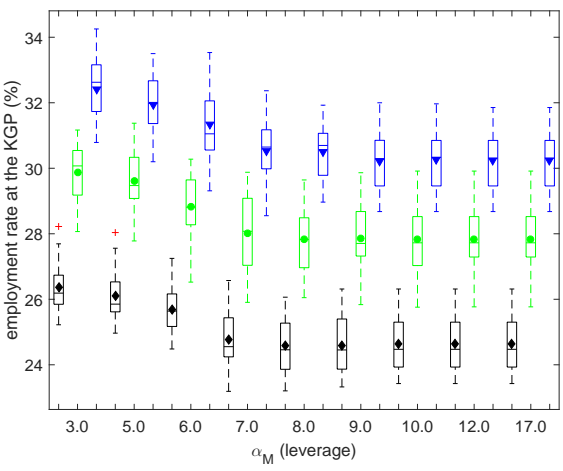

(f)

Fig. 12: The six panels represent the aggregate loans (a), the aggregate capital stock (b), the average energy intensity (c) , the consumption goods price level (d), the employment rate in the consumption goods sector (e), the employment rate in the capital goods sector (f), respectively. The boxplots report for each value of $\alpha_{M}$ considered the time averages from year 2 to year 6 for any of the 25 seeds (simulations). The black boxplots represent the case of decreasing fossilfuel price $\left(\xi_{o}=-0.5 \%\right)$, the green boxplots represent the case of constant fossil-fuel price $\left(\xi_{o}=0.0 \%\right)$ and the blue boxplots the case of increasing fossilfuel price $\left(\left(\xi_{o}=0.5 \%\right)\right)$, considered in the previous figures. The diamond marker represent the mean in the black case, the circle marker in the green case and the triangle in the blue case. 


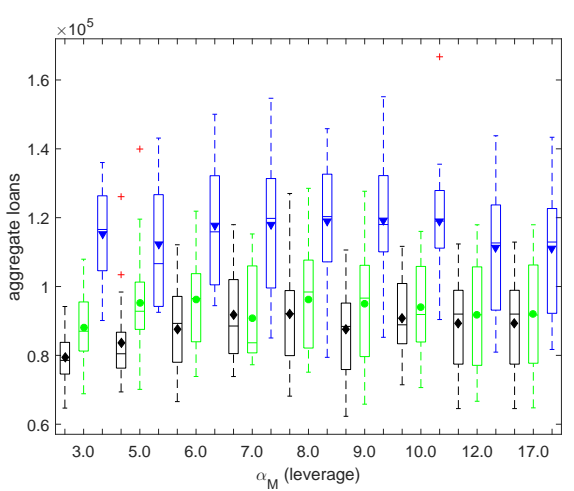

(a)

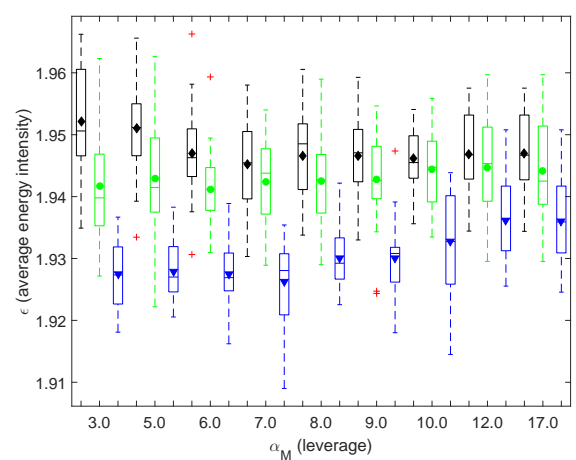

(c)

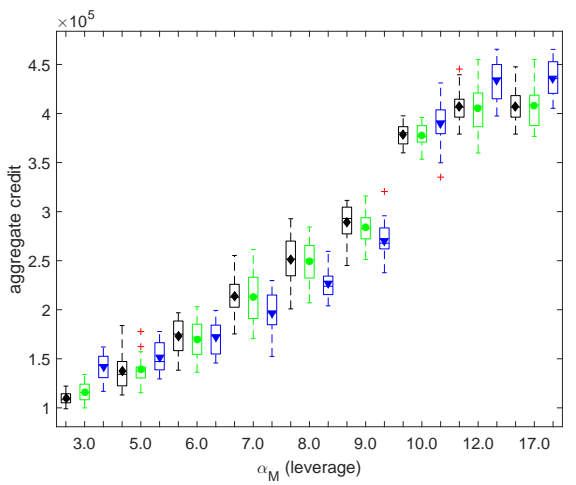

(e)

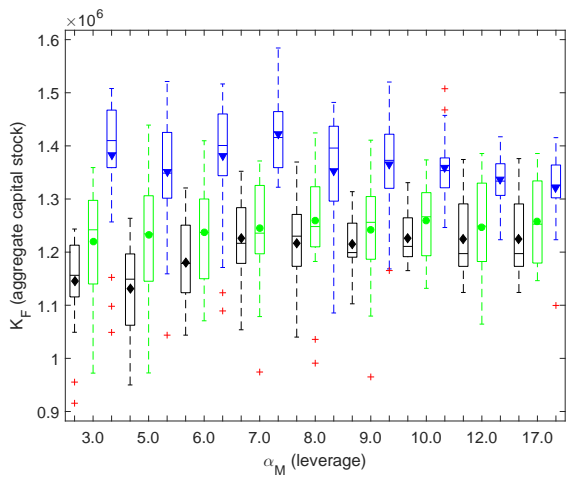

(b)

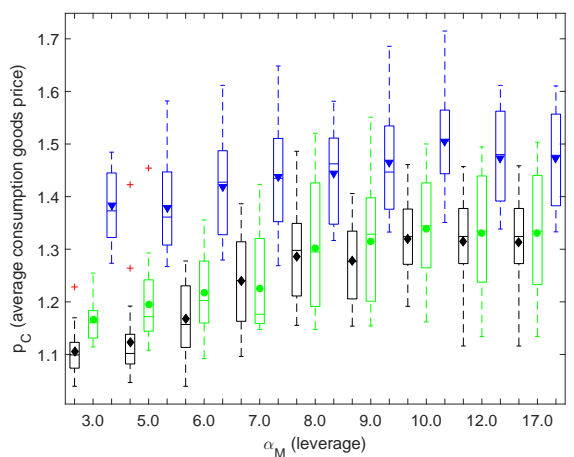

(d)

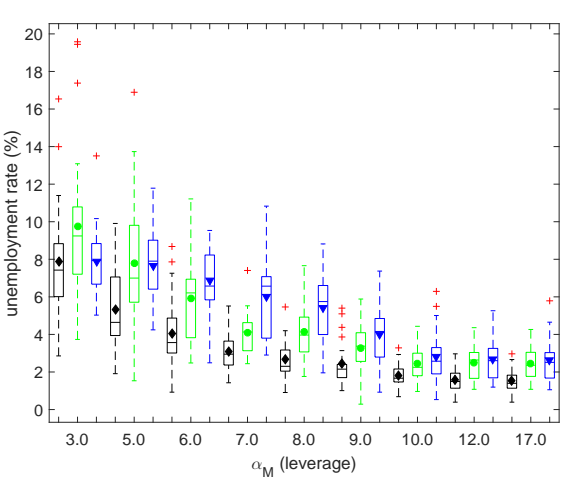

(f)

Fig. 13: The six panels represent the aggregate loans (a), the aggregate capital stock (b), the average energy intensity (c), the consumption goods price level (d), total credit (loans + mortgages) (e), the unemployment rate (f), respectively. The boxplots report for each value of $\alpha_{M}$ considered the time averages from year 7 to year 16 for any of the 25 seeds (simulations). The black boxplots represent the case of decreasing fossil-fuel price $\left(\xi_{o}=-0.5 \%\right)$, the green boxplots represent the case of constant fossil-fuel price $\left(\xi_{o}=0.0 \%\right)$ and the blue boxplots the case of increasing fossil-fuel price $\left(\xi_{o}=0.5 \%\right)$. The diamond marker represent the mean in the black case, the circle marker in the green case and the triangle in the blue case. 
Appendix

A1 - The housing market

The housing market is active every first day of the month. Households play the role of buyers and sellers in the market and can sell or buy one housing unit at a time; housing units are homogeneous. The market is characterized by decentralized exchange and posted prices set by sellers.

Households decision making about house purchase and sale is mainly subject to random behaviour in order to give more relevance to the credit implications and their impact on the economy as a whole, rather than on the behavioural aspects of the housing market. In particular, the parameter $\Phi$ sets the probability for each household to be active in the housing market the first day of each month, unless in the case the household is financially distressed, i.e. she/he is facing mortgage payments (interests + principal) higher than a given fraction $\theta_{f s}$ of her/his income (labor + capital), where both mortgage payments and income refer to the last quarter. If randomly selected to be active, the household can assume the role of buyer or seller with equal likelihood. On the contrary, if financially distressed, say fire sale case, we stipulate that the household enters the market to sell one housing unit at a discounted price with respect to the last average market price, so to increase the likelihood that a transaction takes place, in order to reduce the mortgage burden as well as the debt service. Furthermore, in the case the ratio between quarterly mortgage payments and quarterly income is higher than the threshold $\theta_{d}$, where $\theta_{d}>\theta_{f s}$, then the household defaults on her/his mortgages, which are partially written-off with a consequent loss on the balance sheet of the lending bank.

If a household is randomly selected to enter the housing market with a seller role, then she/he posts one of her/his housing units for sale at higher price than the previous month average market price. In particular, the selling price is higher by a percentage value which is a random draw uniformly distributed between 0 and $\psi_{u p}$. This model feature can be justified based on the assumption that households randomly selected for the seller role do not have any particular necessity to liquidate their housing units. Therefore, we make the reasonable assumption that they are considering the sale of a housing unit only if they can realize a small random gain with respect to the latest average housing market price. Conversely, if a household enters the market with a seller role because financially distressed (fire sale case), then to facilitate liquidation, we assume she/he posts one of her/his housing unit for sale at a lower price than the previous average market price by a percentage value which is a random draw uniformly distributed between 0 and $\psi_{\text {down }}$.

Households that have been randomly selected as buyers are randomly queued and in turn select to purchase the cheapest available housing unit. A transaction takes place at the posted sale price if the household is able to get a mortgage from a bank to cover the entire value of the house. Therefore, for the sake of simplicity, we assume that all granted mortgages are characterized 
Table 1: Housing and energy sectors parameters values used in the simulations

\begin{tabular}{|l|l|l|}
\hline Symbol & Parameter & Value \\
\hline \hline$\Phi$ & probability for a household to be active in the housing market & 0.5 \\
\hline$\theta_{f s}$ & fire sale threshold as a fraction of households income & 0.6 \\
\hline$\theta_{d}$ & mortgage default/write-off threshold as a fraction of households income & 0.7 \\
\hline$\psi_{u p}$ & maximum percentage increase of sale price offer & $2.5 \%$ \\
\hline$\psi_{\text {down }}$ & maximum percentage decrease of sale price offer (fire sale case) & $5 \%$ \\
\hline DSTI & debt service-to-income ratio & 0.5 \\
\hline$\xi_{O}$ & monthly growth rate of fossil fuel price & $0.5,0.0,-0.5 \%$ \\
\hline$\mu_{E}$ & energy price mark-up on fossil fuel price & $100 \%$ \\
\hline$\xi_{K}$ & monthly exponential de-growth rate of capital goods energy intensity & $0.2 \%$ \\
\hline
\end{tabular}

by a loan-to-value (LTV) ratio equal to 1, therefore households do not use their liquidity when buying a housing unit but just money borrowed from a bank. This modelling feature has been chosen in order to avoid a direct and simultaneous interactions of the housing market purchasing behaviour with the saving and investing decision in the financial market. In the case a transaction takes place, the selling agent repays back to the bank the mortgage associated to the sold housing unit. The housing market session closes when all buyers had their turn or there are no more houses for sale. A new housing price is then computed as the average of realized transaction prices.

Banks can provide variable-rate mortgages to households; the annualized mortgage rate is determined on a monthly basis as a mark-up on the rate set by the central bank. Households are due to reimburse the mortgage over a period of 30 years through monthly mortgage payments which include both the interests and the principal instalment. Principal instalments for each mortgage are constant over the repaying period and are computed as a ratio between the initial mortgage amount and 360, i.e. the mortgage duration in months. Monthly interest payments are determined by the outstanding mortgage principal and the annualized mortgage rate divided by 12 , i.e., the number of months in a year. Banks, whenever they receive a mortgage request by a household, assess her/his capability to afford mortgage repayments by comparing household's net income (both labor and capital) earned in the last quarter with household's expected quarterly mortgage payments, including both old outstanding mortgages and the new requested mortgage. Banks grant the requested mortgage provided that the capital requirement rule is fulfilled and the ratio between expected quarterly mortgage payments of the household and her/his latest net quarterly income is lower or equal than a pre-determined threshold, which is called debt-service-to-income (DSTI) ratio.

\section{A2 - Stocks and flows accounting}

This section provides a compact description of the model according to the "stock-flow consistent" approach along the lines introduced by Godley and Lavoie (2012). This approach allows to check the consistency between stocks 
and flows in the model, both at the level of the single agent and at the aggregate one, in line also with post-Keynesian stock-flow-consistent modelling approach, see also Caverzasi and Godin (2015).

A detailed description of the behavioral rules characterizing each agent is reported in Teglio et al. (2017), whereas the details of the housing market mechanism are illustrated in Ozel et al. (2016).

Here, we present three matrices that show:

- Agent class balance sheets

- Sectorial balance sheet

- Stock and monetary flows among sectors.

In particular, Table 2 reports the balance sheets of each agent class that populates the Eurace economy. Table 3 shows all assets and liabilities for each sector (here a sector is the aggregate set of agents belonging to the same class). Finally, Table 4, called transaction flow matrix, shows all the stock and monetary flows among sectors.

\section{A3 - Agent class balance sheets}

The balance sheets of any class of agents populating the Eurace economy is shown in Table 2. Each agent is characterized by liquidity $M$ in the assets side and by equity $E$ in the liabilities side. Households are also characterized by a portfolio of stock shares and government bonds and by housing units in the assets side and by mortgages in the liabilities side. Capital goods and inventories, in the assets side, and debt, in the liabilities side, characterize also the consumption goods producer class. The assets side of the bank agent is also defined by loans and mortgages whereas the liabilities side by deposits and debt. Bonds are also presents in the liabilities side of the government. Finally, the Central Bank is also characterized by loans and government bonds in the assets side and deposits and fiat money in the liabilities side.

\section{A4 - Sectorial Balance sheets}

Table 3 shows, in a compact way, the relation among sectors. In details, a plus (minus) sign corresponds to agents' assets (liabilities) and each column can be read as the aggregated balance sheet of a specific agent. Rows show liabilities and the corresponding claims (assets) among sectors, thus generally adding up to zero. Exceptions are capital and inventories, accumulated by CGPs, housing units belonging to households and households' equity shares, which are issued by CGPs, KGP, power producer and banks and do not add up to zero because of the difference between market price and book value. 
Table 2: Agent class balance sheets

\begin{tabular}{|c|c|c|}
\hline Agent class & Assets & Liabilities \\
\hline $\begin{array}{l}\text { Household } \\
\text { abbrev.: } \mathrm{HH} \\
\text { index: } h=1, \ldots, N_{\text {Hous }}\end{array}$ & $\begin{array}{l}\text { Liquidity: } M_{h} \\
\text { Stock portfolio: } \\
\Sigma_{b} n_{E_{h, b}} p_{E_{b}}+ \\
\Sigma_{f} n_{E_{h, f}} p_{E_{f}}+ \\
n_{E_{h, K}} p_{E_{K}} \\
n_{E_{h, P P}} p_{E_{P P}} \\
\text { Gov Bonds: } n_{h, G} p_{G} \\
\text { Housing units: } X_{h}\end{array}$ & $\begin{array}{l}\text { Mortgages: } U_{h} \\
\text { Equity: } E_{h}\end{array}$ \\
\hline $\begin{array}{l}\text { Consumption Goods Producer } \\
\text { abbrev.: CGP } \\
\text { index: } f=1, \ldots, N_{\text {Firm }}\end{array}$ & $\begin{array}{l}\text { Liquidity: } M_{f} \\
\text { Capital goods: } K_{f} \\
\text { Inventories: } I_{f}\end{array}$ & $\begin{array}{l}\text { Debt: } D_{f}=\sum_{b} \ell_{f, b} \\
\text { Equity: } E_{f}\end{array}$ \\
\hline $\begin{array}{l}\text { Capital Goods Producer } \\
\text { abbrev.: KGP }\end{array}$ & Liquidity: $M_{K}$ & Equity: $E_{K}$ \\
\hline $\begin{array}{l}\text { Power Producer } \\
\text { abbrev.: PP }\end{array}$ & Liquidity: $M_{P P}$ & Equity: $E_{P P}$ \\
\hline $\begin{array}{l}\text { Bank } \\
\text { abbrev.: } \mathrm{B} \\
\text { index: } b=1, \ldots, N_{\text {Bank }}\end{array}$ & $\begin{array}{l}\text { Liquidity: } M_{b} \\
\text { Loans: } \mathcal{L}_{b}=\sum_{f} D_{f} \\
\text { Mortgages: } U_{b}=\sum_{h} U_{b, h}\end{array}$ & $\begin{array}{l}\text { Deposits : } \\
\mathcal{D}_{b}=\sum_{h} M_{b, h}+\sum_{f} M_{b, f}+M_{b, K} \\
\text { Standing facility with the central bank: } \\
D_{b}=\ell_{b, C B} \\
\text { Equity: } E_{b}\end{array}$ \\
\hline $\begin{array}{l}\text { Government } \\
\text { abbrev.: G }\end{array}$ & Liquidity: $M_{G}$ & $\begin{array}{l}\text { Outstanding government bonds value : } \\
D_{G}=n_{G} p_{G} \\
\text { Equity: } E_{G}\end{array}$ \\
\hline $\begin{array}{l}\text { Central Bank } \\
\text { abbrev.: CB }\end{array}$ & $\begin{array}{l}\text { Liquidity: } M_{C B} \\
\text { Loans to banks: } \mathcal{L}_{C B}= \\
\sum_{b} D_{C B, b}= \\
\text { Gov Bonds: } n_{C B, G} p_{G}\end{array}$ & $\begin{array}{l}\text { Outstanding fiat money: Fiat } C B \\
\text { Deposits: } \\
\mathcal{D}_{C B}=\sum_{b} M_{C B, b}+M_{C B, G} \\
\text { Equity: } E_{C B}\end{array}$ \\
\hline
\end{tabular}

Table 2. Balance sheets of any class of agents populating the Eurace economy. Balance sheet entries in the table have a subscript character, that is the index of the agent to which the variable refers. In some cases, we can find two subscript characters, where the second one refers to the index of the agents representing the balance sheets counterparts. For instance, $D_{f}$ refers to the total loans of firm $f$, i.e. a liability, and $\mathcal{L}_{b}$ refers to the total loans of bank $b$, i.e. an asset. $\ell_{f, b}$ (or $\ell_{b, f}$ ) refer to the loans issued by banks $b$ to firms $f$. Of course $\sum_{b} \mathcal{L}_{b}=\sum_{f} D_{f}$ represents a balance sheet identity, that is verified along the entire simulation. $n_{E_{h, x}}$ represent the number of outstanding equity shares of agents $x$ held by households $h$. The market price of the equity shares is given by $p_{E_{x}}$. The stock portfolio's value of household $h$ is then computed as: $\sum_{x} n_{E_{h, x}} p_{E_{x}}$. Government bonds' number and market price are given by $n_{G}$ and $p_{G}$, respectively. 


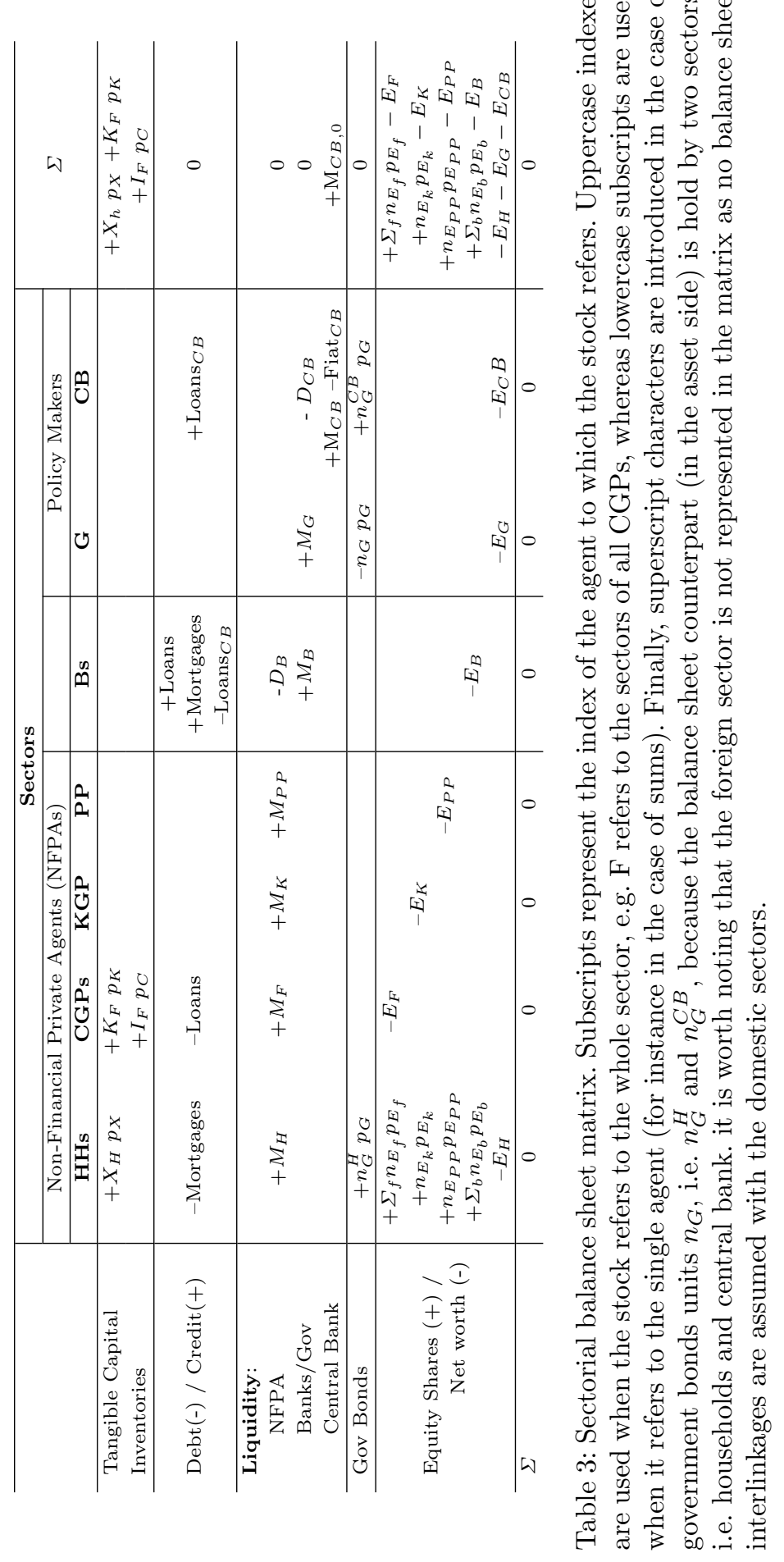


Finally, it is worth noting that in table 3 , the difference between fiat money (on the liability side) and central bank liquidity (on the asset side) is always constant (and equal to the initial central bank liquidity $M_{C B, 0}$. Fiat money is the money created by the central bank to provide loans to commercial banks, when they are in liquidity shortage, or to buy government bonds in the secondary market, through quantitative easing operations. Households, that sell government bonds to the central bank, deposit the sale proceeds at their own banks, while the money lend to banks by the central bank is lent to households of firms, then in turn deposited again in the banking sector. Therefore, in both cases, the liquidity of the banking sector is increased by an amount equal to the new Fiat money created and this additional liquidity is deposited by banks at the central bank, then increasing central bank liquidity by an amount always equal to the Fiat money originally created. It is worth noting however that the money supply in the economy can variate independently from the fiat money created by the central bank, because it endogenously raises every time a bank grants a new loan or mortgage and it decreases when the loan or mortgage is paid back.

\section{A5 - Stock and monetary flows among sectors}

All the stock and monetary flows among agents are described in the transaction flow matrix (table 4), where the current account describes the flows of revenues (plus sign) and payments (minus sign) that agents get and make. Rows show the monetary flows among agents. The result of agents' transactions is the net cash flow.

The capital account section of Table 4 describes the balance sheet changes related to each sector. 


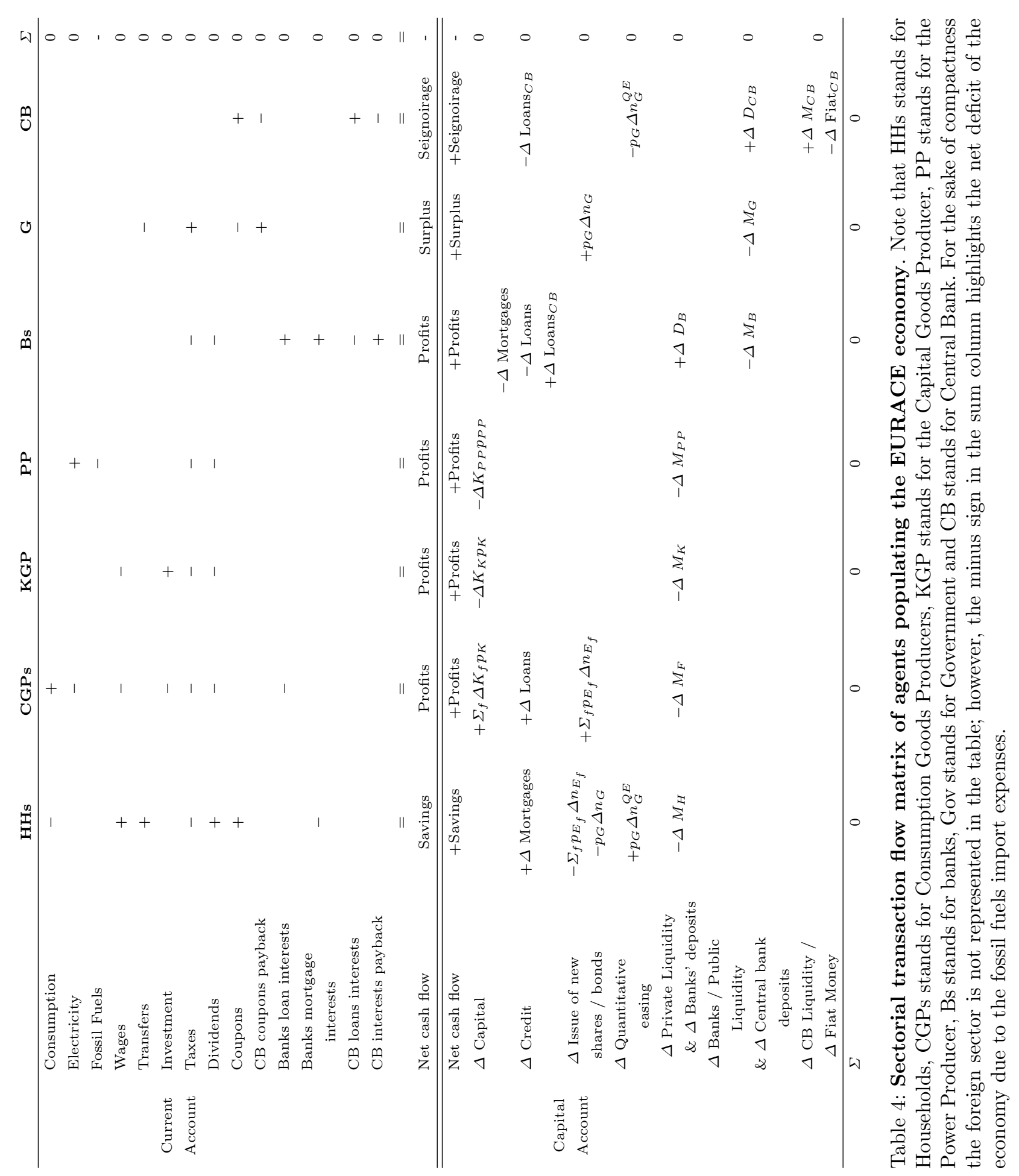

